\title{
A- $\pi-D-\pi-A$ based porphyrin for solution processed small molecule bulk heterojunction solar cells
}

\author{
Challuri Vijay Kumar Lydia Cabau ; Emmanuel N. Koukaras : Abhishek \\ Sharma; Ganesh D. Sharma and Emilio Palomares \\ Institute of Chemical Research of Catalonia (ICIQ), Avda. Països Catalans 16, E-43007 \\ Tarragona, Spain \\ Molecular Engineering Laboratory, Department of Physics, University of Patras,
} Patras, 26500 GR, Greece

Department of Electronics and Communication, LNMIIT, Jamdoli, Jaipur, India $R \& D$ Center for Engineering and Science, JEC Group of Colleges, Jaipur Engineering email:gdsharma273@gmail.com;sharmagd_in@yahoo.com

Catalan Institution for Research and Advance Studies (ICREA), Avda. Lluis Companys 23, E-08010 Barcelona, Spain. E-mail: epalomares@iciq.es

In this article, we have designed and synthesized a porphyrin with the following molecular architecture $\mathrm{A}-\pi-\mathrm{D}-\pi-\mathrm{A}$ in which ethyl rhodanine end capping groups were linked to the core porphyrin donor via an octyl thiophene-ethynylene $\pi$ bridge denoted as VC117 and used it as an electron donor along with ([6,6]-phenyl $\mathrm{C}_{71}$ butyric acid methyl ester) $\left(\mathrm{PC}_{71} \mathrm{BM}\right)$ as an electron acceptor for the fabrication of solution processed organic solar cells. The solution processed $\mathrm{BHJ}$ organic solar cell with an optimized weight ratio of $1: 1 \mathrm{VC117}: \mathrm{PC}_{71} \mathrm{BM}$ in THF (tetrahydrofuran) showed an overall power conversion efficiency (PCE) of $2.95 \%$ with short circuit current $J_{\mathrm{sc}}=8.34 \mathrm{~mA}$ $\mathrm{cm}^{-2}$, open circuit voltage $V_{\mathrm{oc}}=0.82 \mathrm{~V}$ and fill factor $\mathrm{FF}=0.43$. Nonetheless, when the active layer of the solar cell was processed from a mixture of $4 \% \mathrm{v} / \mathrm{v}$ of pyridine in THF solvent, it achieved a PCE value of $4.46 \%$ and further improved up to $5.50 \%$ after thermal annealing. This is ascribed to the enhancement of both the $J_{\mathrm{sc}}$ and FF values. The higher value of $J_{\mathrm{sc}}$ is explained by the increased absorption profile of the blend, the higher incident photon to current efficiency (IPCE) response and the better crystallinity of the active layer when processed with solvent additives and thermal annealing while the enhancement of FF is due to the better charge transport capability and the charge collection efficiency of the latter device. 


\section{Introduction}

Bulk heterojunction organic solar cells consist of a blend of a conjugated polymer donor and a fullerene derivative as the electron acceptor and convert the energy of sunlight directly into electrical energy. They have attracted ever increasing interest due to their low cost, roll to roll manufacturing, environmentally friendly processing, lightweight properties and mechanical flexibility. 1 Bulk heterojunction organic solar cells (BHJOSCs) using donor-acceptor (D-A) copolymers as electron donors and $\mathrm{PC}_{71} \mathrm{BM}$ have shown a power conversion efficiency (PCE) over 10\% in single BHJ solar cells and $10.6 \%$ (ref. 2) in tandem solar cells. ${ }^{3}$ This progress is a direct result of the development of different materials including electron donor ${ }^{4}$ and electron acceptor materials,,$\underline{\underline{s}}$ along with the innovation and optimization in device processing and engineering. ${ }^{6}$ In spite of these advances in polymer based BHJ solar cells, there are two main disadvantages of conjugated polymers i.e. the purity of materials and variations in their molecular weights which make synthesis of these materials with photovoltaic properties in a systematic manner difficult. $?$ In recent years, solution processed small molecule solar cells have been emerging as a competitive alternative to those based on copolymers due to their advantages, which include versatile chemical structures, easier energy level control, mobility tuning and less batch to batch variations,,$\stackrel{8}{ }$ and PCE in the range of 8 $10 \%$ has been reported for these solar cells. ${ }^{2}$

In a solution processed BHJ small molecule solar cell, the donor small molecule plays a very important role in absorbing incident light on the device, and it should possess a strong and wide absorption profile that closely matches with the solar spectrum. In this regard, porphyrin derivatives, owing to their very well established potential as light harvesting antennae for efficient energy and electron transfer processes in biological systems, appear to be very attractive as donors in organic solar cells..$^{10}$ These materials display absorption spectra with intense Soret band at 400-450 $\mathrm{nm}$ and moderate $\mathrm{Q}$ bands at 500-700 $\mathrm{nm}$, due to their $\pi$-conjugated macrocyclic framework. Moreover, their electronic, spectroscopic and physical properties can be appropriately tuned by synthetically modifying the substituents of the macrocyclic ring and/or the metal in the central cavity. ${ }^{11}$ Porphyrin derivatives have been successfully employed as sensitizers for dye sensitized solar cells ${ }^{\underline{12}}$ and some of them have shown a PCE of more than $12-13 \% .{ }^{13}$ But, the use of porphyrin as the donor in solution processed BHJ organic solar cells is limited due to their low solubility in common organic solvents, which is one of the most important requirements for these types of devices. However, the appropriate selection of peripheral substituents can increase the solubility of porphyrins. Matsuo et al. have reported the synthesis of soluble porphyrins consisting of tetraethyl porphyrin cores with two aromatic and two aliphatic groups at trans positions and used them as donors along with $\mathrm{PC}_{60} \mathrm{BM}$ as the electron acceptor 
for solution processed BHJ organic solar cells and achieved a PCE of 2.5\%. . $^{14}$ With the above consideration in mind, many porphyrin derivatives have been synthesized by different research groups and used as donors for solution processed BHJ solar cells and moderate PCEs have been reported. ${ }^{15}$ Peng et al. employed a porphyrin molecule with less bulky substituents at the periphery as a donor material along with $\mathrm{PC}_{61} \mathrm{BM}$ as the acceptor for solution processed organic solar cells and achieved a PCE up to $7.23 \%$. ${ }^{16 a}$ Recently, Gao et al. have achieved a PCE of $8.08 \%$ for solution processed BHJ solar cells with porphyrin having a low bandgap of $1.37 \mathrm{eV} . \underline{16 \mathrm{~b}}$

For conjugated small molecules with acceptor-donor-acceptor structures, many promising end groups have been reported, including dicyanovinyl $(\mathrm{CN}),{ }^{17}$ alkyl cyanoacetate ${ }^{18}$ and 3-ethylrodanine. ${ }^{19}$ Recently, Liu et al. have designed a small molecule with 3-octylrodanine as the electron-withdrawing end-group and BDT-T as the core unit and reported a PCE of $8.02 \%$ for solution processed BHJ organic solar cells, using this small molecule as the donor and $\mathrm{PC}_{71} \mathrm{BM}$ as the electron acceptor. molecular structure with a conjugated donor backbone and electron withdrawing terminals has several advantages for use in BHJ organic solar cells: (i) high mobility with a planar structure and efficient $\pi-\pi$ interactions, (ii) a low bandgap resulting from intramolecular charge transfer and (iii) good film quality owing to a long conjugated backbone with dispersed alkyl chains similar to polymers. Recently, we have designed an $\mathrm{A}-\pi-\mathrm{D}-\pi-\mathrm{A}$ porphyrin small molecule in which di-cyanovinyl substituted thiophene (A) was linked by ethynylene to the porphyrin core with high solubility and used it as the electron donor along with $\mathrm{PC}_{71} \mathrm{BM}$ as the electron acceptor for solution processed solar cells and achieved a PCE of $5.34 \% . \underline{20}$

In continuation of our research work in the field of small molecules for solution processed BHJ solar cells, we report the design and synthesis of an $\mathrm{A}-\pi-\mathrm{D}-\pi-\mathrm{A}$ porphyrin small molecule in which ethyl rhodanine end capping groups were linked to the core porphyrin donor via an octyl thiophene-ethynylene $\pi$ bridge. An ethynylene link makes the octyl thiophene moiety coplanar to the porphyrin core thus promoting an extensive $\pi$-conjugated region. We have used this porphyrin small molecule as a donor along with $\mathrm{PC}_{71} \mathrm{BM}$ as the acceptor for the fabrication of $\mathrm{BHJ}$ solution processed organic solar cells. Moreover, we have shown that the nanomorphology of the VC117: $\mathrm{PC}_{71} \mathrm{BM}$ active layer could be improved by the solvent additive pyridine with enhanced balanced charge transport and a PCE of up to $5.50 \%$ has been achieved for the optimized BHJ organic solar cell. The enhancement in the PCE is mainly due to the improved values of $J_{\mathrm{sc}}$ and $\mathrm{FF}$, attributed to the combination of light harvesting efficiency, exciton dissociation efficiency and charge transport ability, due to the improved nanoscale morphology and interpenetrating pathways, induced by the solvent additives. 


\section{Experimental details}

\section{General}

Unless stated otherwise, all reagents were purchased from commercial sources and used without further purification. Dichloromethane, pyrrole, pyridine, dichloroethane, ethanol and THF were distilled before use. Ethyl rhodanine, $\mathrm{DDQ}_{4}, \mathrm{Pd}_{2}(\mathrm{dba})_{3}, \mathrm{AsPh}_{3}$, and $N$-bromosuccinimide (NBS) were purchased from Sigma-Aldrich. Dry THF and toluene were obtained by passing them through an activated alumina column on a PureSolv ${ }^{\mathrm{TM}}$ solvent purification system (Innovative Technologies, Inc., MA). Flash column chromatography was carried out using Silica gel 60, 40-63 $\mu \mathrm{m}$ (Panreac Química SLU) as the stationary phase. Size exclusion chromatography was carried out in a large elution column $(1000 \mathrm{~mm} \times 38 \mathrm{~mm})$ with Biobead SX3 (Bio-Rad Laboratories, Inc.) as the stationary phase. The eluent was passed through the column under gravity. 5-Bromo-3,3-dioctyl-2,2:5,2-terthiophene-2-carbaldehyde $\left(\mathrm{Br}_{3} \mathrm{TCHO}\right)^{21}$ and octyloxy diacetylene porphyrin ${ }^{22}$ were synthesized as per the earlier reported procedure.

\section{Experimental}

UV-vis absorption spectra were recorded in a $1 \mathrm{~cm}$ path-length quartz cell using a Shimadzu model 1700 spectrophotometer. Steady state fluorescence spectra were recorded using a Spex model Fluoromax-3 spectrofluorometer using a $1 \mathrm{~cm}$ quartz cell. All ${ }^{1} \mathrm{H}$ and ${ }^{13} \mathrm{C}$ NMR spectra were recorded on a Bruker AV 300 and AV 500 instruments, respectively, at a constant temperature of $300 \mathrm{~K}$, unless otherwise stated. ${ }^{1} \mathrm{H}$ spectra were referenced to tertramethylsilane. ESI mass spectra were recorded on a Water Quattro micro (Water Inc., USA). Cyclic voltammetry experiments were carried out with a PC-controlled $\mathrm{CH}$ instrument model CHI620C electrochemical analyzer. Flash column chromatography was carried out using Silica gel 60, 40-63 $\mu \mathrm{m}$ (Panreac Química SLU) as the stationary phase. Size exclusion chromatography was carried out in a large elution column $(1000 \mathrm{~mm} \times 38 \mathrm{~mm})$ with Biobead SX3 (Bio-Rad Laboratories, Inc.) as the stationary phase. The eluent was passed through the column under gravity.

Synthesis of 3.1 ( $300 \mathrm{mg}, 0.519 \mathrm{mmol}$ ) was dissolved in a solution of dry chloroform (30 mL) and two drops of piperdine and 3-ethyrhodanine (2) (417 mg, $2.59 \mathrm{mmol})$ were added and the resulting solution was heated to reflux and stirred for 24 hours under argon. The reaction mixture was cooled to room temperature, and then water was added. The crude product was extracted into $\mathrm{CHCl}_{3}$, and the organic layer was dried over $\mathrm{Na}_{2} \mathrm{SO}_{4}$. The solvent was removed under reduced pressure and the crude product was purified by column chromatography on silica gel using $\mathrm{CH}_{2} \mathrm{Cl}_{2}$ and hexane (1:1) as

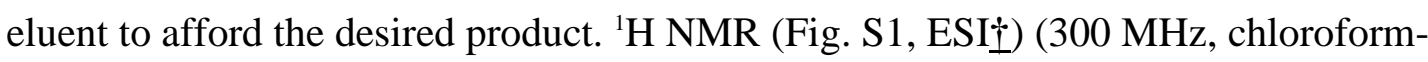
d) $\delta 7.75(\mathrm{~s}, 1 \mathrm{H}), 7.17(\mathrm{~s}, 1 \mathrm{H}), 7.16(\mathrm{~d}, 1 \mathrm{H}, J=4.0 \mathrm{~Hz}), 7.02(1 \mathrm{H}, \mathrm{d}, J=3.6 \mathrm{~Hz}), 6.88$ 
$(1 \mathrm{H}, \mathrm{s}), 4.16(2 \mathrm{H}, \mathrm{q}), 2.75(4 \mathrm{H}, \mathrm{m}), 1.61(20 \mathrm{H}, \mathrm{m})$, and $0.83(9 \mathrm{H}, \mathrm{m}) .{ }^{13} \mathrm{C}$ NMR $(75$ $\mathrm{MHz}, \mathrm{CDCl}_{3}$ ) (Fig. S2, ESI亡̀) $\delta$ 191.42, 166.73, 140.64, 140.22, 138.51, 136.51, 136.03, $134.74,134.48$, 132.22, 130.68, 126.58, 126.13, 124.19, 120.13, 110.58, 39.25, 31.28, 29.92, 29.71, 29.07, 28.87, 28.80, 28.74, 28.67, 28.614, 22.01, 13.44, and 11.64. MS (MALDI-TOF) (Fig. S3, ESI $\dot{\perp}$ ): calcd for [M]+, 721.1239 .

Synthesis of VC117. In a dry Schlenck tube, $\mathbf{4}^{22}(150 \mathrm{mg}, 0.138 \mathrm{mmol})$ and $\mathbf{3}(249 \mathrm{mg}$, $0.34 \mathrm{mmol})$ were dissolved in a mixture of dry THF $(20 \mathrm{~mL})$ and $\mathrm{NEt}_{3}(5 \mathrm{~mL})$ and the solution was degassed with di-nitrogen for $10 \mathrm{~min}$; $\mathrm{Pd}_{2}(\mathrm{dba})_{3}(75 \mathrm{mg}, 0.08 \mathrm{~m} \mathrm{~mol})$ and $\mathrm{AsPh}_{3}(168 \mathrm{mg}, 0.552 \mathrm{~m} \mathrm{~mol})$ were added to the mixture. The solution was refluxed for $12 \mathrm{~h}$ under a nitrogen atmosphere. The solvent was removed under reduced pressure and the crude product was purified by silica gel column chromatography using chloroform and hexane $(1: 1)$ as eluent and subsequent size exclusion chromatography using THF as eluent to obtain a purple solid. ${ }^{1} \mathrm{H}-\mathrm{NMR}$ (Fig. S4, ESI $\doteq$ ) (300 MHz, THF-d8) $\delta_{\mathrm{H}} 9.48$ (4H, d), 8.75 (4H, d), 7.87 (s, 2H), 7.69 (t, 2H), 7.59 (d, 2H), 7.47 (s, 2H), 7.41 (d, 2H), $7.36(\mathrm{~d}, 2 \mathrm{H}), 7.02(\mathrm{~d}, 4 \mathrm{H}), 4.16(\mathrm{~m}, 4 \mathrm{H}), 3.66(\mathrm{~m}, 4 \mathrm{H}), 2.96(\mathrm{~m}, 8 \mathrm{H}), 1.30(\mathrm{~m}, 60 \mathrm{H})$, $0.86(\mathrm{~m}, 44 \mathrm{H})$, and $0.64(\mathrm{~m}, 30 \mathrm{H}) .{ }^{13} \mathrm{C}$ NMR $(75 \mathrm{MHz}$, THF-d8) (Fig. S5, ESII) $\delta 191.42,166.53,160.03,150.97,150.56,141.05,140.14,140.58,138.59$, $137.73,137.12,135.62,135.02,134.45,131.52,131.16,129.73,129.59,127.91$, $127.59,126.81,124.89,123.31,120.99,120.60,115.49,104.57,99.47,98.68,88.05$, $39.52,37.18,34.14,32.79,31.92$, 31.94, 31.55, 30.52, 30.26, 30.08, 29.80, 29.70, 29.60, 29.52, 29.43 29.29, 28.87, 28.79, 25.41, 22.61, 22.31, 13.51, 13.37, and 11.36. MS (MALDI-TOF) (Fig. S6, ESI $\mathrm{C}_{136} \mathrm{H}_{170} \mathrm{~N}_{6} \mathrm{O}_{6} \mathrm{~S}_{10} \mathrm{Zn} \mathrm{C}, 68.90 ; \mathrm{H}, 7.23 ; \mathrm{N}, 3.54 ; \mathrm{O}, 4.05 ; \mathrm{S}, 13.52$. Found C, 71.46; H, 8.16; N, 2.97; S, 10.57 .

We would like to point out that VC117 was purified by consecutive flash chromatography, size exclusion chromatography and also HPLC. However, although this combination of techniques was effective to remove almost all major impurities, a by-product was still present (as can be seen in the ${ }^{1} \mathrm{H}-\mathrm{NMR}$ ). It is estimated that the final product has a degree of purity higher than $95 \%$. The implications on the device solar cell performance are described below.

\section{Device fabrication and characterization}

$\mathrm{BHJ}$ organic solar cells were fabricated using the glass/ITO/PEDOT:PSS/VC117:PC ${ }_{71} \mathrm{BM} / \mathrm{Al}$ device architecture. Indium tin oxide (ITO) patterned substrates were cleaned by ultrasonic treatment in aqueous detergent, deionized water, isopropyl alcohol, and acetone sequentially, and finally dried under ambient conditions. The anode consisted of glass substrates percolated with ITO, modified by spin coating with a PEDOT:PSS layer $(60 \mathrm{~nm})$ for hole transport and heated for $10 \mathrm{~min}$ at $100^{\circ} \mathrm{C}$. Mixtures of $\mathrm{VC117}$ with $\mathrm{PC}_{71} \mathrm{BM}$ with weight ratios of 1 : $0.5,1: 1$, and $1: 1.5$ in tetrahydrofuran (THF) were prepared and then spin-cast onto 
the PEDOT:PSS layer and dried overnight at ambient temperature. For the $\mathrm{VC117}: \mathrm{PC}_{71} \mathrm{BM}$ blend processed from 1, 2, 3, 4 and 5\% v/v of pyridine in THF solvent mixture only the $1: 1$ weight ratio mixture was used. The total concentration of mixture was $10 \mathrm{mg} \mathrm{ML}^{-1}$ for each active layer. The approximate thickness of the active layers was $90 \mathrm{~nm}$. We have prepared a VC117: $\mathrm{PC}_{71} \mathrm{BM}$ active layer processed under different conditions: VC117: $\mathrm{PC}_{71} \mathrm{BM}$ (processed with THF) for device

$\mathrm{A}, \mathbf{V C 1 1 7}: \mathrm{PC}_{71} \mathrm{BM}$ (pyridine/THF cast) for device $\mathrm{B}$ and $\mathrm{VC117}: \mathrm{PC}_{71} \mathrm{BM}$ (pyridine/THF cast and subsequent thermal annealing at $110^{\circ} \mathrm{C}$ for $10 \mathrm{~min}$ ) for device C. For thermal annealing, the active layer cast from pyridine/THF was placed on a hot plate at $110{ }^{\circ} \mathrm{C}$ for $10 \mathrm{~min}$. Finally, the aluminum (Al) top electrode was thermally deposited on the active layer in a vacuum of $10^{-5}$ Torr through a shadow mask with an area of $0.20 \mathrm{~mm}^{2}$. All devices were fabricated and tested in ambient atmosphere without encapsulation. The hole-only and electron-only devices with

ITO/PEDOT:PSS/VC117: $\mathrm{PC}_{71} \mathrm{BM} / \mathrm{Au}$ and ITO/Al/VC117: $\mathrm{PC}_{71} \mathrm{BM} / \mathrm{Al}$ architectures were also fabricated in an analogous way, in order to measure the hole and electron mobility, respectively. The current-voltage $(J-V)$ characteristics of the BHJ organic solar cells were measured using a computer controlled Keithley 238 source meter in the dark and under a simulated AM $1.5 \mathrm{G}$ illumination of $100 \mathrm{~mW} \mathrm{~cm}^{-2}$. A xenon light source coupled with an optical filter was used to provide stimulated irradiance at the surface of the devices. The incident photon to current efficiency (IPCE) of the devices was measured by illuminating the device through a light source and monochromator and the resulting current was measured using a Keithley electrometer under short circuit conditions.

XRD measurements were performed on a Bruker D8 Advanced model diffractometer with $\mathrm{Cu} \mathrm{K} \alpha$ radiation $(\lambda=1.542 \AA)$ at a generator voltage of $40 \mathrm{kV}$.

\section{Results and discussion}

\section{Synthesis and characterization}

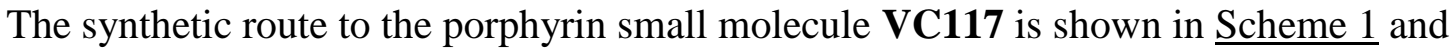
the target molecule based on the A- $\pi-\mathrm{D}-\pi-\mathrm{A}$ architecture is shown in Scheme 2 . The VC117porphyrin molecule was synthesised via the Sonagashira coupling reaction of bromo terthiophene rhodanine (3) with diacetylene porphyrin in the presence of dry THF, $\mathrm{NEt}_{3}, \mathrm{Pd}_{2}(\mathrm{dba})_{3}$ and $\mathrm{AsPh}_{3}$. The intermediate (3) was synthesised via Knoevenagel condensation of ethylrodanine with bromo terthiophene aldehyde in the presence of piperidine. The important intermediates and the targeted porphyrin small molecule VC117 were well characterized by ${ }^{1} \mathrm{H}-\mathrm{NMR},{ }^{13} \mathrm{C}$ NMR, and MALDI TOF mass spectroscopy. VC117 was purified by consecutive flash chromatography and size exclusion chromatography. This combination of techniques was found to be effective for purifying the molecule to acceptable levels for device fabrication. The central atom porphyrin unit was functionalized with the octyl terthiophene $\pi$ bridge and acceptor ethyl rhodanine as the terminal unit. The symmetrical structure of the porphyrin small molecule is expected to enhance the $\pi-\pi$ stacking interactions which could be beneficial for high mobility. The terminal unit ethyl rhodanine acceptor adjusts the HOMOLUMO energy levels of the porphyrin small molecule. The introduction of the long alkyl chain to porphyrin and terthiophene increases their solubility in common organic solvents. 

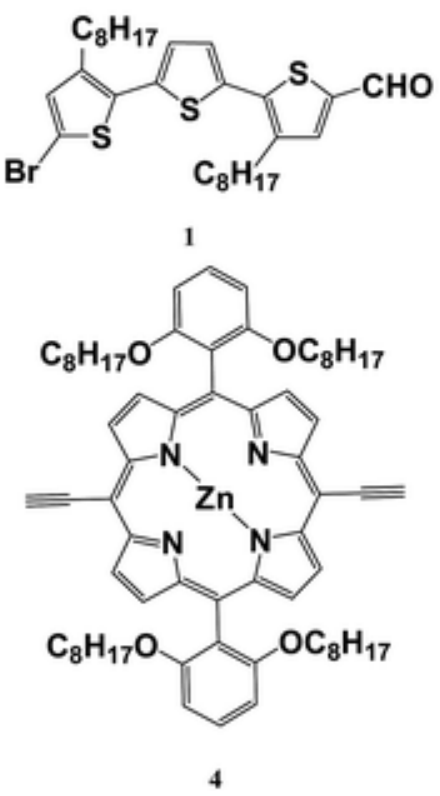

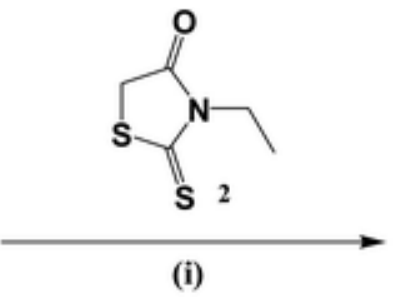

(i)

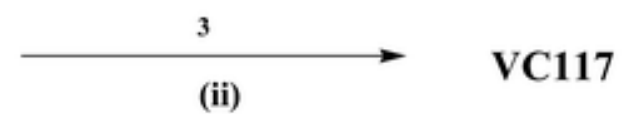

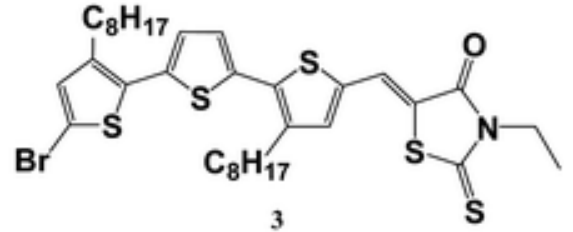

Scheme 1 Synthetic route to VC117. (Reaction conditions): (i) dry chloroform, pipperdine reflux, $12 \mathrm{~h}$ and (ii) $\mathrm{Pd}_{2}(\mathrm{dba})_{3}, \mathrm{AsPh}_{3}$, dry THF, $\mathrm{NEt}_{3}$, reflux $12 \mathrm{~h}$.
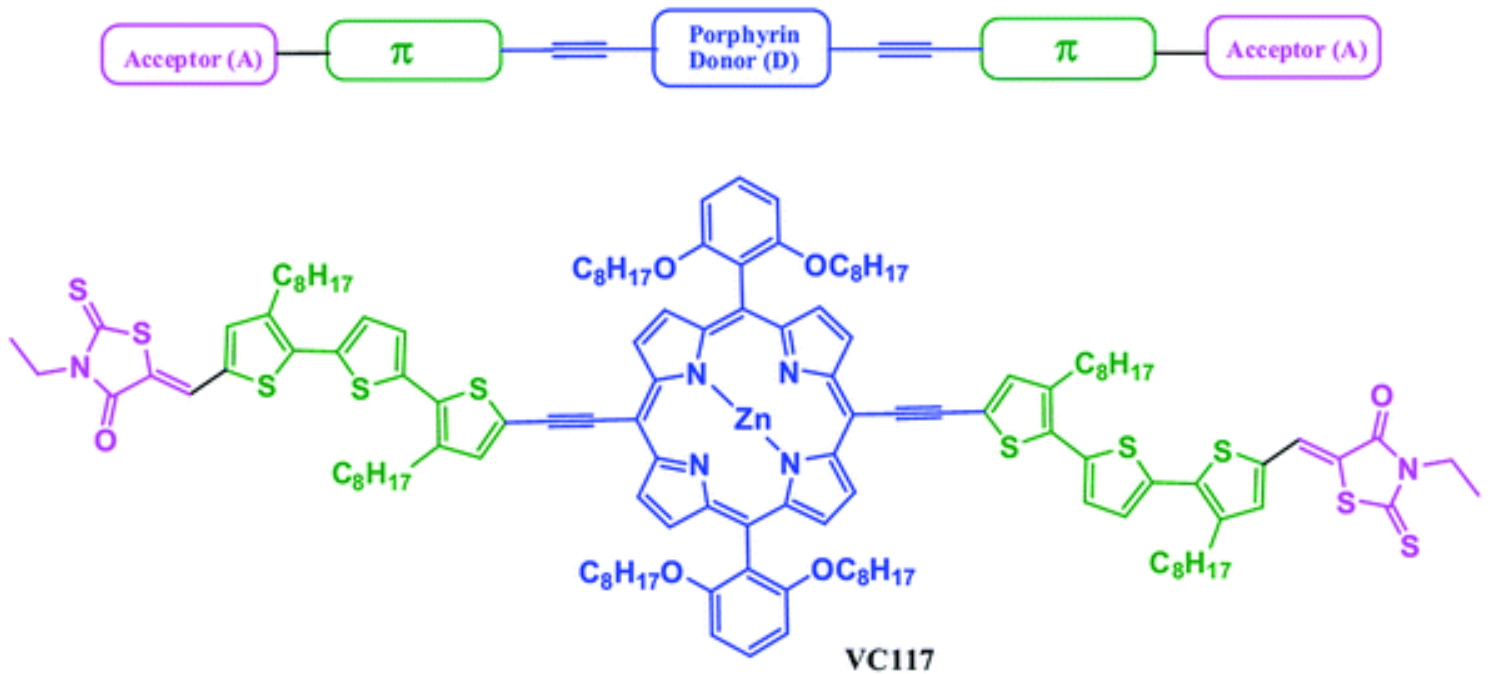
Scheme 2 General architecture of the $A-\pi-D-\pi-A$ small molecule and the molecular structure of VC117.

\section{Photophysical and electrochemical properties}

The normalized optical absorption spectra of VC117 in dilute THF solution and the thin film cast from the THF solvent is shown in Fig. 1 and the data are compiled in Table 1. VC117exhibits a strong Soret band in the wavelength range of 400-550 nm with an absorption peak at $467 \mathrm{~nm}$ and a moderate $\mathrm{Q}$ band in the wavelength range of 620-720 $\mathrm{nm}$ with a peak around $682 \mathrm{~nm}$, which are the typical characteristics of ethynyl link based porphyrins. $\underline{23}$ The Soret band of VC117 broadens and also red shifts and the Q band also red shifts and intensifies, as compared to other porphyrins which may be attributed to intramolecular charge transfer (ICT) between the donor and acceptor units. These spectral changes indicate an effective $\pi$-elongation through the porphyrin core, octyl thiophene-ethynylene $\pi$ bridge and ethyl rhodanine and better conjugation for VC117. ${ }^{24}$ As compared to the absorption spectrum in solution, the thin film absorption spectra showed a slight red shift and broadening in both Soret and Q bands. A red shift of about $18 \mathrm{~nm}$ in the $\mathrm{Q}$ band is attributed to strong intermolecular interactions in the solid state. The optical bandgap of VC117 is estimated from the onset of the absorption spectrum in the thin film and is about $1.62 \mathrm{eV}$. This porphyrin molecule exhibits wide absorption from 400 to $760 \mathrm{~nm}$ with high absorption coefficients owing to the efficient conjugation in the backbone structure and intramolecular charge transfer between the terminal acceptor units and core donor through the $\pi$-linker.

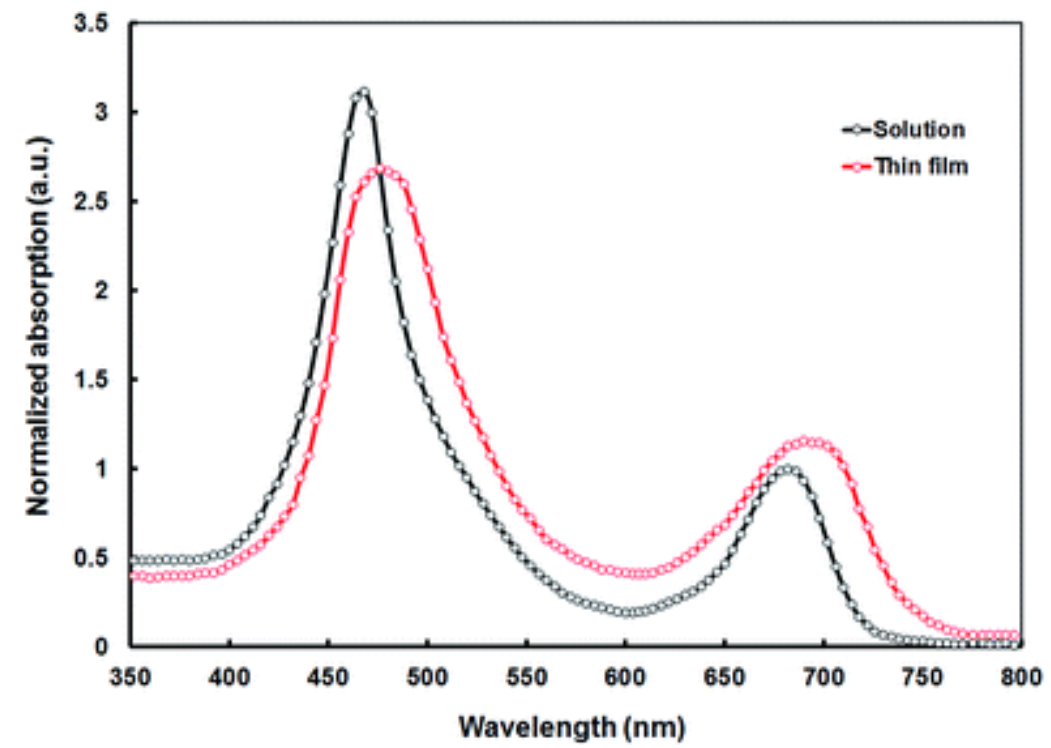

Fig. 1 Normalized absorption spectra of VC117 in THF solution and the thin film cast from the THF solution. 
Table 1 Absorption, emission and electrochemical properties of VC117

$\boldsymbol{E}_{0-}$

Material $\lambda_{\text {abs }}(\mathrm{nm}) \quad \lambda_{\mathrm{em}}(\mathrm{nm}) \lambda_{\text {abs }}(\mathrm{nm}) E_{\mathrm{g}(\mathrm{opt})}(\mathrm{eV}) E_{\text {ox }}\left(\mathrm{V} v s . \mathrm{Fc} / \mathrm{Fc}^{+}\right)_{\mathrm{o}}(\mathrm{eV}) E_{\text {номо }}(\mathrm{ev}) E_{\text {Luмо }}(\mathrm{ev})$

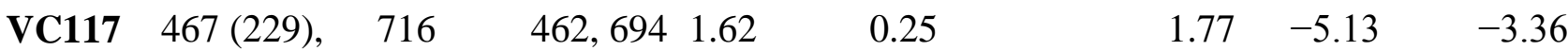

$682(73)$

$a$ Measured in THF. In parentheses molar extinction coefficient at $\lambda_{\text {abs }}\left(\right.$ in $\left.10^{3} \mathrm{M}^{-1} \mathrm{~cm}^{-1}\right)$. $b$ Measured in a thin film cast from THF solution. $c E_{0-0}$ was determined from the intersection of absorption and

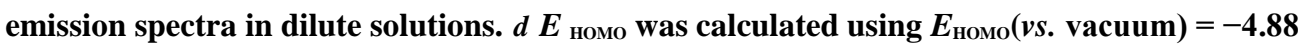

$-E_{\text {ox }}\left(v s . \mathrm{Fc} / \mathrm{Fc}^{+}\right)$. $e E_{\text {цимо }}$ was calculated using $E_{\mathrm{Lumo}}=E_{\text {номо }}+E_{0-0 \cdot} f$ Calculated from the onset absorption edge in the absorption spectra in the thin film.

Cyclic voltammetry (CV) was used to estimate the highest occupied molecular orbital (HOMO) of VC117. The potential was internally calibrated using the ferrocene/ferrocenium $\left(\mathrm{Fc} / \mathrm{Fc}^{+}\right)$ redox couple ( $4.8 \mathrm{eV}$ below the vacuum level). The HOMO which is $-5.13 \mathrm{eV}$ for VC117 was estimated from the onset oxidation and reduction potential. The LUMO energy level was determined using $E_{\mathrm{LUMO}}=E_{\text {Номо }}-E_{\mathrm{O}-\mathrm{O}} . E_{\mathrm{O}-\mathrm{O}}$ is the energy between the energy transition between the lowest vibrational ground state and the lowest vibrational excited state and calculated from the intersection of absorption and emission spectra of small molecules in solution (Fig. $\mathrm{S7}, \mathrm{ESI}+$ ). The calculated LUMO energy level of VC117 is $-3.36 \mathrm{eV}$, which is above the LUMO energy level of $\mathrm{PC}_{71} \mathrm{BM}(-4.1 \mathrm{eV})$ that acts as an electron acceptor, which generates a large driving force for the transfer and separation of photogenerated charge carriers at the $D-A$ interface.

\section{Theoretical calculations}

We have additionally performed a theoretical study on the VC117 molecular structures within the framework of density functional theory (DFT) and time-dependent density functional theory (TD-DFT).

The initial geometry optimization calculations were performed employing the gradient corrected functional PBE $\underline{25}$ of Perdew, Burke and Ernzerhof. The def-SVP basis set ${ }^{26}$ was used for all of the calculations. At this stage of the calculations, to increase the computational efficiency (without loss in accuracy), the resolution of the identity method $^{27}$ was used for the treatment of the two-electron integrals. Subsequent geometry optimization was further performed using the hybrid exchange-correlation functional $\mathrm{B} 3 \mathrm{LYP}^{28}$ as well as Truhlar's meta-hybrid exchange-correlation functional M06,29 and 
the same basis set. Tight convergence criteria were placed for the SCF energy (up to $10^{-7} \mathrm{Eh}$ ) and the one-electron density (rms of the density matrix up to $10^{-8}$ ) as well as for the norm of the Cartesian gradient (residual forces both average and maximum smaller than $1.5 \times 10^{-5}$ a.u.) and residual displacements (both average and maximum smaller than $6 \times 10^{-5}$ a.u.). Solvent effects were included for the THF using the integral equation formalism variant of the Polarizable Continuum Model (IEFPCM), as implemented in the Gaussian package. $\frac{30}{}$ TD-DFT excited state calculations were performed to calculate the optical gap of VC117 using the same functionals and basis set on the corresponding ground state structures. The UV/Vis spectra were calculated using the B3LYP and M06 functionals. The first round of geometry optimization was performed using the Turbomole package. .11 All of the follow up calculations were performed using the Gaussian package. $\frac{30}{}$

The first round of calculations was geometry optimization using initial geometries with various orientations of the moieties that form the VC117 structure. To increase the computational efficiency of the next rounds, for which the hybrid B3LYP and metahybrid M06 functionals were used, the alkyl groups were truncated to ethyl groups. Vibrational analysis on the optimized structure VC117 did not reveal any vibrational modes with imaginary eigenfrequencies, i.e. the final optimized structures are true local (if not global) minimum. The main inner body of the structures is highly planar, this includes the porphyrin structure up to (and including) the first thiophene moiety. The two outer rings are coplanar which is mainly as the result of the unsaturated linking carbon. The thiophene group that links the outer and inner structure forms dihedral angles $\sim 17^{\circ}$ to $22^{\circ}$ and $\sim 28^{\circ}$ to $32^{\circ}$ with the inner and outer structure, respectively, depending on the functional and the presence of the solvent. The planes of the phenyl groups linked to porphyrin form almost normal dihedral angles to the main body plane. We have calculated the HOMO and LUMO energy levels and the optical gaps, defined here as the energetically lowest allowed vertical electronic excitation, employing the PBE, M06, and B3LYP functionals. In Table 2, in addition to the frontier orbitals' energy levels, we also provide the optical gap, the main contributions to the first excitation, as well as the wavelength of the first excitation and of the excitations with the largest oscillator strengths.

Table 2 Calculated properties of VC117. Specifically HOMO and LUMO energies (eV), HOMO-LUMO gap (eV), HL, optical gap (eV), OG, with corresponding oscillator strengths, $f$, the wavelengths of the first excitation and excitations with the largest oscillator strengths, the main contributions to the first excited state, and the dipole moment (D), $\mu$ 
HOM LUMO HL OG

Main

$\mathrm{O}(\mathrm{eV})(\mathrm{eV}) \quad(\mathrm{eV}) \quad(\mathrm{eV}) \lambda_{1 \mathrm{st} / \max }(\mathrm{nm}) f$ contributions $\mu(\mathrm{D})$

\begin{tabular}{|c|c|c|c|c|c|c|}
\hline \multirow[t]{2}{*}{ PBE } & -4.42 & $\begin{array}{lll}-3.40 & 1.02 & 1.17\end{array}$ & 1062 & 1.69 & $\begin{array}{l}\mathrm{H} \rightarrow \mathrm{L}(85 \%), \mathrm{H} \rightarrow \mathrm{L}+2 \\
(13 \%)\end{array}$ & 2.85 \\
\hline & $-4.52^{\underline{a}}$ & $-3.53^{\underline{a}} 0.99^{\underline{a}} 1.11^{\underline{a}}$ & $1113^{\underline{a}}$ & $2.31^{\underline{a}}$ & $\begin{array}{l}\mathrm{H} \rightarrow \mathrm{L}(91 \%), \mathrm{H} \rightarrow \mathrm{L}+2 \\
(8 \%)^{\underline{a}}\end{array}$ & \\
\hline \multirow[t]{2}{*}{ B3LYP } & -4.86 & $\begin{array}{lll}-2.91 & 1.95 & 1.71\end{array}$ & $727 / 509 / 440 / 399$ & 2.89 & $\mathrm{H} \rightarrow \mathrm{L}(94 \%)$ & 3.30 \\
\hline & $-4.97^{a}$ & $-3.05^{a} 1.92^{a} 1.63^{a}$ & $\begin{array}{l}760 / 526 / 463 / 443 / \\
403^{a}\end{array}$ & $2.88^{\underline{a}}$ & $\mathrm{H} \rightarrow \mathrm{L}(94 \%)^{\underline{a}}$ & $4.24^{a}$ \\
\hline \multirow[t]{2}{*}{ M06 } & -5.12 & $\begin{array}{lll}-2.85 & 2.27 & 1.78\end{array}$ & $\begin{array}{l}696 / 488 / 430 / 419 / \\
404 / 369\end{array}$ & 2.88 & $\begin{array}{l}\mathrm{H} \rightarrow \mathrm{L}(86 \%), \mathrm{H}-1 \rightarrow \mathrm{L}+3 \\
(5 \%), \mathrm{H} \rightarrow \mathrm{L}+2(4 \%)\end{array}$ & 3.39 \\
\hline & $-5.26^{\underline{a}}$ & $-3.01^{\underline{a}} 2.25^{\underline{a}} 1.71^{\underline{a}}$ & $\begin{array}{l}724 / 556 / 497 / 465 / \\
430 / 408 / 380^{\underline{a}}\end{array}$ & $3.09^{\underline{a}}$ & $\begin{array}{l}\mathrm{H} \rightarrow \mathrm{L}(89 \%), \mathrm{H}-2 \rightarrow \mathrm{L}+3 \\
(4 \%)^{\underline{a}}\end{array}$ & $4.32^{a}$ \\
\hline
\end{tabular}

$a$ Values when solvent effects are taken into account for tetrahydrofuran.

In addition to the B3LYP functional we have also performed our calculations employing the M06 functional. The M06 meta-hybrid functional was chosen since it provides leveled performance over transition types. $\frac{32.13 a}{W}$ We provide results using all three functionals, which can additionally be used for comparison with the literature. The HOMO-LUMO (HL) gap calculated using the hybrid B3LYP functional is slightly smaller than that obtained using the meta-hybrid M06 functional and however, the calculated optical gaps are practically the same for both functionals. In Table 2, we also provide the character of the first allowed excitations only for contributions larger than $4 \%$. The first excitation, as calculated by each of the functionals, clearly exhibits a strong single-configuration character, with only marginal secondary contributions.

In Fig. 2, we have plotted the isosurfaces (isovalue $=0.02$ ) of the HOMO and LUMO, as well as the next nearest frontier orbitals of VC117 which are involved in transitions with strong contributions to the first excitation. The HOMO extends over all of the main body of the structures that is planar and includes the first (inner) thiophene and the linking thiophene moieties. The LUMO is delocalized mainly on the inner part of the structures, but also extends over all of the ring groups, however with smaller 
contributions. We also show the HOMO-1, HOMO-1, and LUMO+2, LUMO+3 isosurfaces since transitions between them contribute to the first excitation, as shown in Table 2. The delocalizations exhibited by these orbitals vary, with the HOMO-2 and LUMO+3 mainly on the porphyrin, and the HOMO-1 and LUMO+2 over the thiophene chain or the terminating thiophenethiazolidin4one (TPTAO) ring groups. To quantify the contributions of the moieties to the frontier orbitals, we have calculated the total and partial density of states (PDOS). The PDOS for VC117 is shown in Fig. 3. We partition the structure into the diPhenylPorphyrine, dPPorph, central structure, the first thiophene group bonded to the porphyrin, TPa, the thiophene that links the inner and outer structure, TPL, the TPTAO outer ring, and all the alkyl groups collectively. The HOMO is dominated by contributions from the dPPorph and TPA groups by 50\% and $33.6 \%$, respectively, as well as a significant contribution of $9.9 \%$ from the linking thiophene TPL. A similar pattern is found for the LUMO to which the dPPorph and TPA contribute $52.3 \%$ and $21.3 \%$, respectively, however in this case with significant contributions from TPTAO at $18.7 \%$ and from TPL at $7.4 \%$. Thus the transitions from HOMO to LUMO are not expected to result in significant charge transfer. The near frontier orbitals exhibit different characters, specifically, the contributions from TPA, TPTAO, dPPorph and TPL are $30.5 \%$ (0.0\%), 33.1\% (0.0\%), 6.4\% (99.9\%), and 28.1\% (0.0\%) for HOMO-1 (HOMO-2). Similarly, the corresponding contributions to LUMO+2 (LUMO+3) are 5.2\% (0.0\%), 69.8\% (0.0\%), $19.1 \%(99.8 \%)$, and $5.6 \%(0.0 \%)$. These are in agreement with our earlier observations on the orbital delocalization. From the pattern that emerges, any charge transfer from HOMO-1 to LUMO+3 transitions is compensated by that from HOMO to LUMO+2 transitions. On the other hand, no charge transfer is expected from HOMO-2 to LUMO+3 transitions. Overall, the first excitation does not result in charge transfer. The first significant contribution (5.1\%) from the aliphatic groups is noted at lower energies, about $-6.7 \mathrm{eV}$ which corresponds to the HOMO-10 level. 

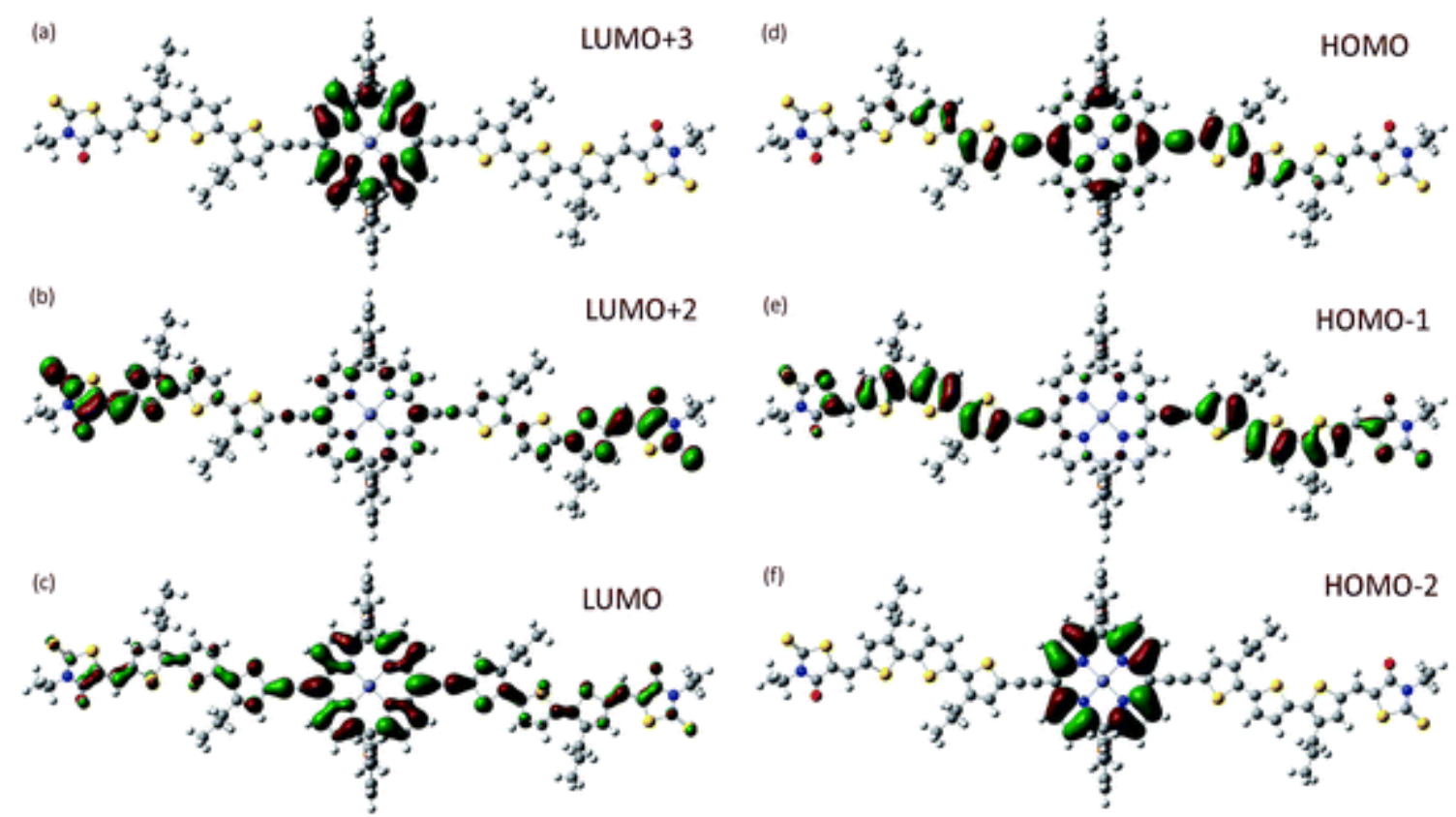

Fig. 2 Frontier and near frontier orbitals of VC117, involved in transitions that contribute to the first excitation (alkyl groups have been shortened).

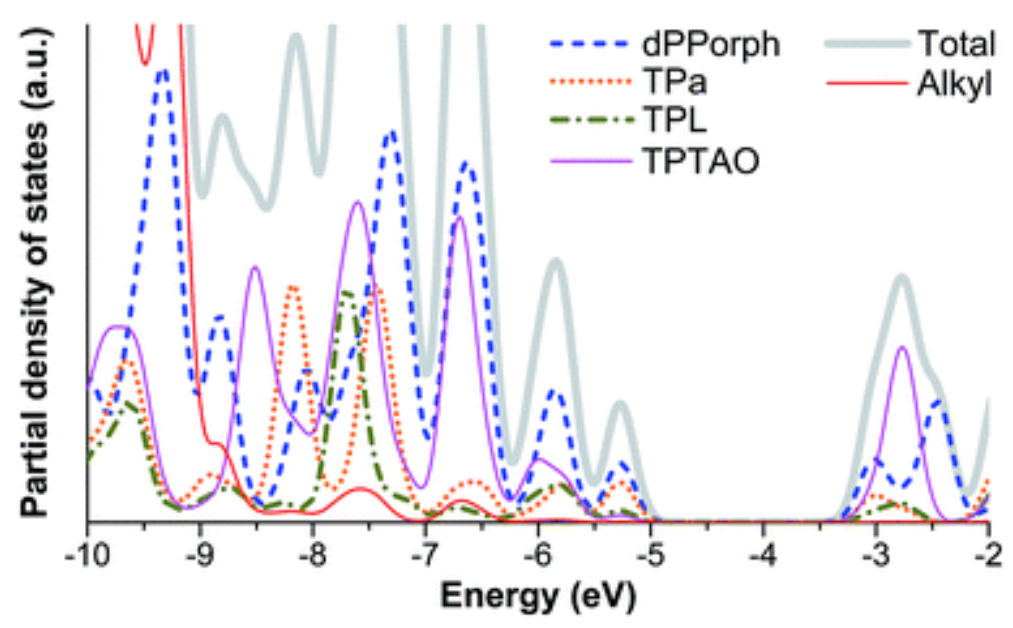

Fig. 3 Total and partial density of states of VC117 (calculated using the M06 functional).

In Fig. 4, we show the UV/Visual absorption spectra of the VC117 structure calculated the TD-DFT/M06 level of theory, both accounting for solvent effects for THF and in the gas phase. The spectra have been produced by convoluting Gaussian functions with HWHM $=0.18 \mathrm{eV}$ centered at the excitation wavenumbers. In Fig. SI-1 (see ESI ${ }^{\dagger}$ ) we also provide the corresponding spectra calculated using the B3LYP functional, which only slightly overestimates 
the wavelengths and retains all the main characteristics compared with that using M06 and the experimental spectra. The absorption spectra of the two structures exhibit two main bands that are located in the high and low wavelength regions. The low wavelength region exhibits a finer structure which manifests as a side bump at lower wavelengths. The first band is centered at $724 \mathrm{~nm}$ and the second at $497 \mathrm{~nm}$. The wavelengths of the excitations with the largest oscillator strengths within these bands are listed in Table 2.

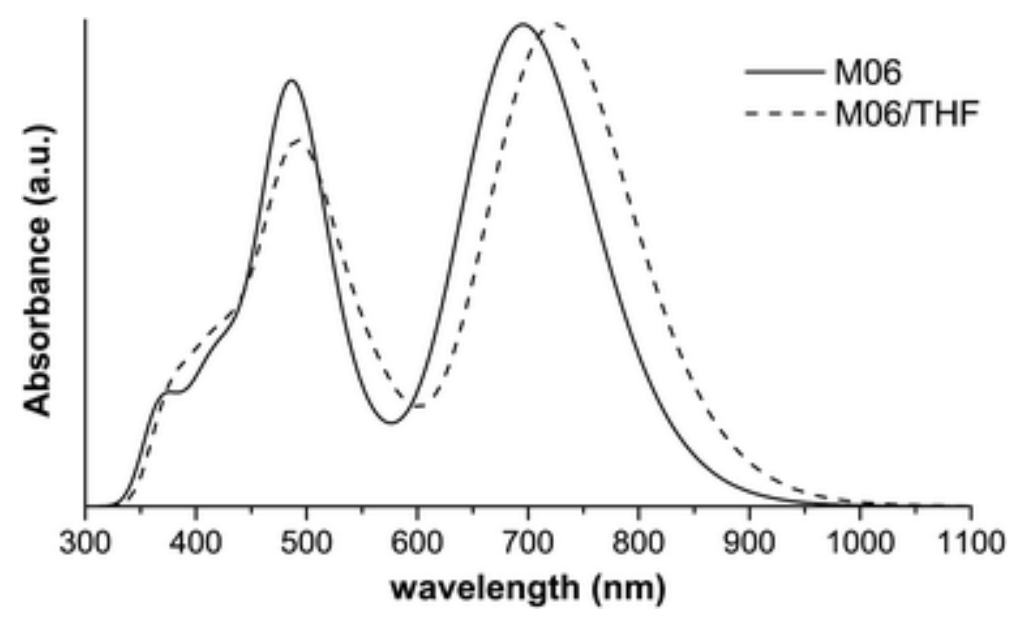

Fig. 4 Theoretical UV/Vis absorption spectrum of VC117 (calculated using the M06 functional).

\section{Photovoltaic properties}

The photovoltaic performance of the organic solar cell that uses the BHJ active layer with a mixture of donor and acceptor materials is significantly influenced by the relative concentrations of these components used for the preparation of the active layer as there should a balance between the absorbance of incident photons and the subsequent charge transport process within the active layer. When the concentration of the acceptor material is low, the electron transporting ability will be limited while with the higher amount of acceptor concentration, the absorbance and hole transport ability of the active layer will be decreased. In our system, the optimum device performance was observed in a blend of $1: 1$ weight ratio of the mixture $\mathrm{VC117}$ and $\mathrm{PC}_{71} \mathrm{BM}$ in THF, after testing the devices with a series of three different weight ratios $(1: 0.5,1: 1$ and $1: 1.5)$. From the normalized absorption spectrum of this blend $\mathrm{VC117}: \mathrm{PC}_{71} \mathrm{BM}(1: 1)$ (Fig. 5), which shows the combination of both $\mathrm{VC117}$ and $\mathrm{PC}_{71} \mathrm{BM}$ absorption characteristics, it becomes obvious that both moieties participate in light absorption and thus photocurrent generation. 


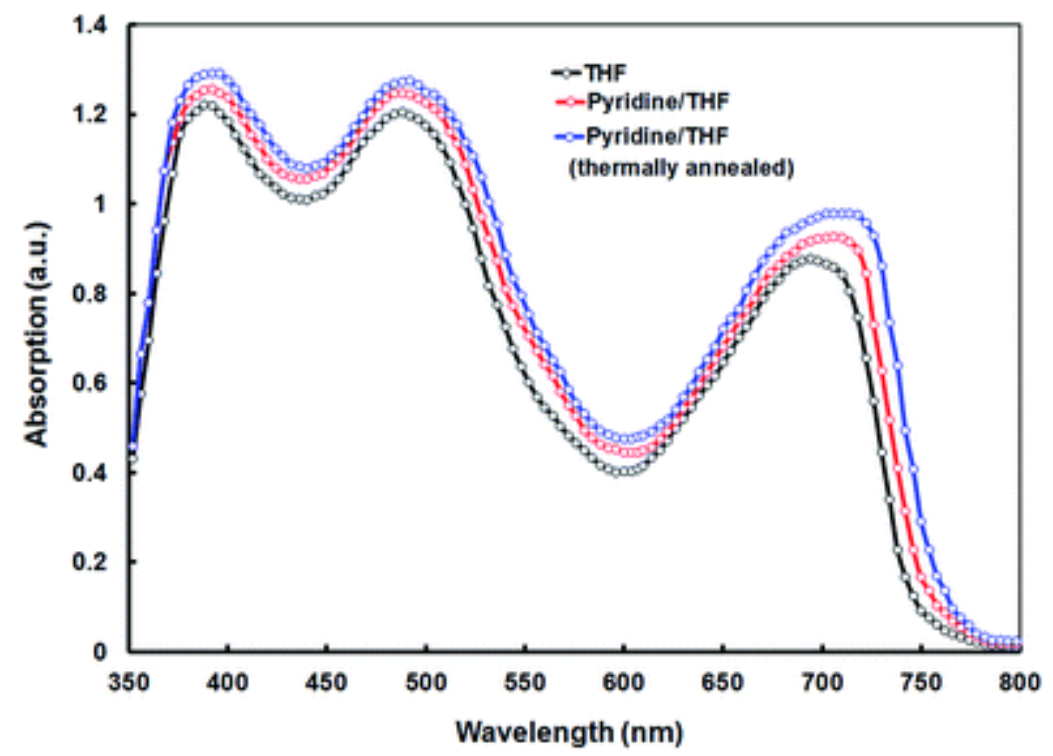

Fig. 5 Normalized absorption spectra of the VC117:PC ${ }_{71} \mathrm{BM}(1: 1)$ thin film processed under different conditions.

The current-voltage characteristics of the device based on the optimized VC117:PC $\mathrm{C}_{71} \mathrm{BM}(1: 1)$ active layer processed from the THF solvent (device $A$ ), under stimulated solar illumination $\left(100 \mathrm{~mW} \mathrm{~cm}^{-2}\right)$, is shown in Fig. 6a and the photovoltaic parameters are listed in Table 3. The device showed an overall PCE of $2.95 \%$ with $J_{\mathrm{sc}}=8.38 \mathrm{~mA} \mathrm{~cm}^{-2}, V_{\mathrm{oc}}=0.82 \mathrm{~V}$ and FF $=0.43$. The $V_{\text {oc }}$ of the device based on VC117 is respectable, however it is lower than that with the porphyrin dye $\mathrm{V} C 62, \underline{20}$ which may be related to the higher value of the HOMO energy level of VC117 $(-5.13 \mathrm{eV})$ as compared to VC62 $(-5.44 \mathrm{eV})$. The incident photon to current conversion efficiency (IPCE) of the device based on VC117:PC ${ }_{71} \mathrm{BM}(1: 1, \mathrm{THF})$ is shown in Fig. $6 \mathrm{~b}$ and it is found that this spectrum is closely related to absorption spectrum of the VC117: $\mathrm{PC}_{71} \mathrm{BM}$ blend (as shown in Fig. 5), indicating that both VC117 and $\mathrm{PC}_{71} \mathrm{BM}$ contribute to photocurrent generation. 

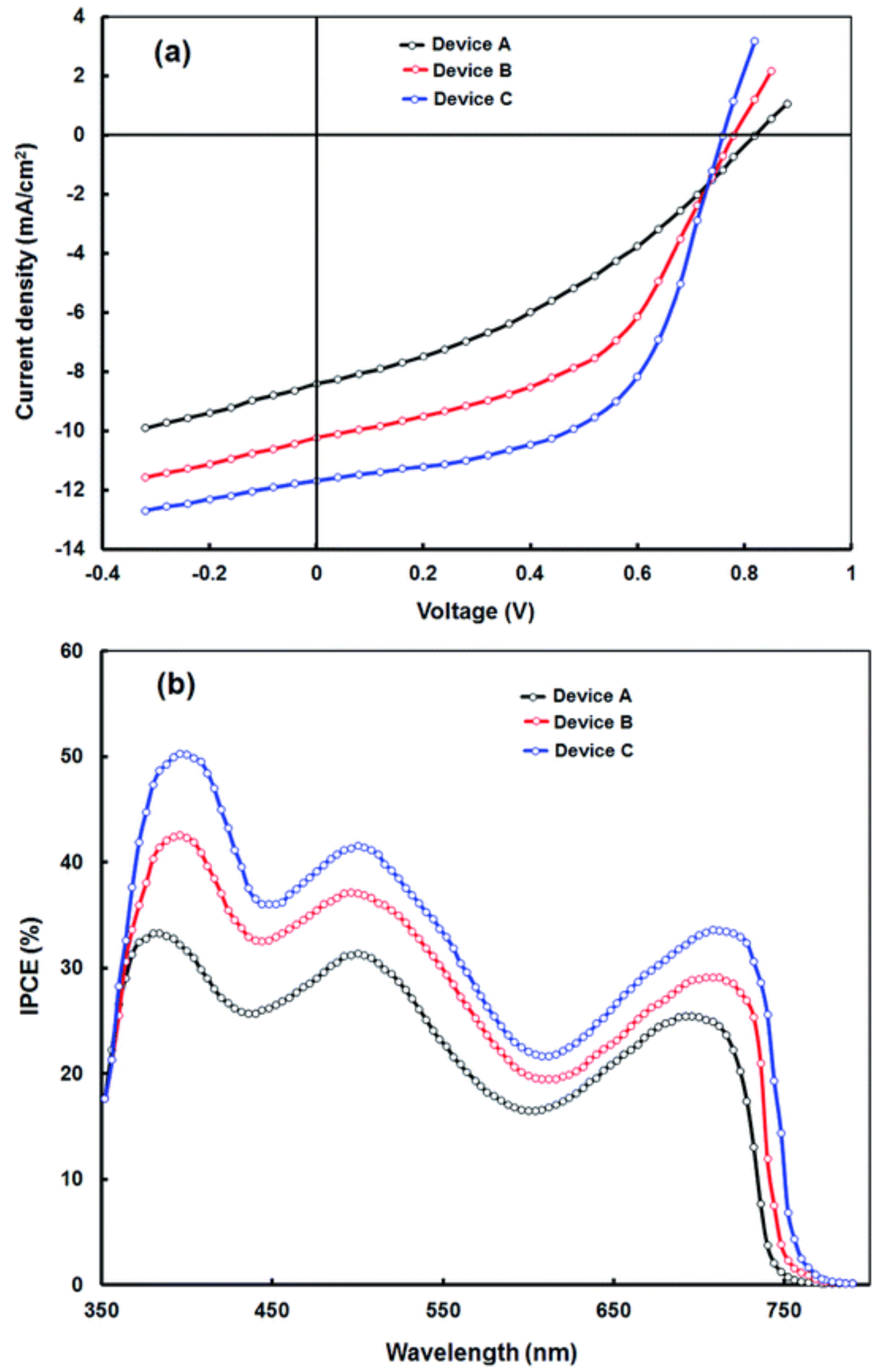
Fig. 6 (a) Current-voltage characteristics under illumination and IPCE spectra of BHJ organic solar cells based on VC117: $\mathrm{PC}_{71} \mathrm{BM}$ blends processed under different conditions.

\begin{tabular}{|c|c|c|c|c|c|c|}
\hline Solvent & $\begin{array}{l}J_{\text {sc }}(\mathbf{m A} \\
\left.\mathbf{c m}^{-2}\right)\end{array}$ & $V_{\text {oc }}(\mathrm{V})$ & $\begin{array}{ll} & \text { PCE } \\
\text { FF } & (\%) \\
\end{array}$ & $R_{\mathrm{s}}(\mathrm{Ohm})$ & $\begin{array}{l}R_{\text {sh }}(\mathrm{Ohm} \\
\left.\mathbf{c m}^{2}\right)\end{array}$ & $\begin{array}{l}\mu\left(\mathrm{cm}^{2} \mathbf{V}^{-1}\right. \\
\left.\mathrm{s}^{-1}\right)\end{array}$ \\
\hline THF (device A) & 8.38 & 0.82 & 0.432 .95 & 54 & 213 & $6.21 \times 10^{-6}$ \\
\hline Pyridine/THF (device B) & 10.22 & 0.78 & 0.564 .46 & 31 & 256 & $5.05 \times 10^{-5}$ \\
\hline Pyridine/THF ${ }^{a}$ (device C) & 11.67 & 0.76 & 0.625 .50 & 18 & 324 & $8.45 \times 10^{-5}$ \\
\hline
\end{tabular}

Table 3 Photovoltaic parameters of organic solar cells based on the VC117:PC ${ }_{71} \mathrm{BM}$ active layer processed under different conditions

Nevertheless, the overall PCE value of the organic solar cell based on the $\mathrm{VC117}: \mathrm{PC}_{71} \mathrm{BM}$ active layer processed from THF is smaller than that reported in the literature when other small molecules are used as donors. The inferior performance can also be attributed to the fact, as mentioned in the Experimental section, that the VC117 has purity above 95\% only. A seminal paper by Heeger and co-workers in 2011 describes how "small amounts of impurity, even one part in one thousand" can lead to a noticeable decrease in solar cell efficiency. ${ }^{33}$ Nonetheless, the $V_{\text {oc }}$ of the present device is excellent $\left(V_{\mathrm{oc}}=0.82 \mathrm{~V}\right)$ and the lower PCE value is mainly due to the low values of both $J_{\mathrm{sc}}$ and FF. These two parameters are directly related to the light harvesting efficiency of the active layer and the resulting charge generation as well as to the charge transport and collection to the respective electrodes, processes that depend on the film morphology. A well defined nanomorphology and phase separation between donor and acceptor components in the active layer within the range of the exciton diffusion length are necessary for efficient exciton dissociation and charge transport. ${ }^{34}$ It is reported that by controlling the morphology of the active layer, induced by appropriate treatment methodologies, i.e., thermal annealing, ${ }^{35}$ solvent annealing ${ }^{\underline{36}}$ and solvent additives, ${ }^{37}$ the photovoltaic performance of BHJ organic solar cells based on either conjugated polymers or small molecules can be significantly improved.

Particularly, the choice of solvent plays a very important role and influences greatly the overall PCE of organic solar cells based on the BHJ active layer. Recently, the solvent additive method had been used to improve the performance of BHJ organic solar cells using porphyrins as electron donors and $\mathrm{PC}_{71} \mathrm{BM}$ as electron acceptors with remarkable results. ${ }^{15.16}$ Aiming to improve the overall PCE value of our device based on the 
optimized VC117: $\mathrm{PC}_{71} \mathrm{BM}$ active layer, we have employed the solvent additive treatment method using a small amount of pyridine as the solvent additive (device B), as it is known to be more effective than other solvent additives for porphyrin based BHJ solar cells. We have added different amounts of pyridine $(1,2,3,4$ and 5\% v) and found that $4 \% \mathrm{v}$ is the optimized concentration (device B). In order to improve the PCE of the device, we further thermally annealed the solvent additive cast VC117:PC ${ }_{71} \mathrm{BM}$ film at $110{ }^{\circ} \mathrm{C}$ for $10 \mathrm{~min}$ (device $\mathrm{C}$ ). The $J-V$ characteristics and IPCE spectra of the devices $\mathrm{B}$ and $\mathrm{C}$ are shown in Fig. 6a and b, respectively. The devices $\mathrm{B}$ and $\mathrm{C}$ showed a PCE of $4.46 \%\left(J_{\mathrm{sc}}=10.22 \mathrm{~mA} \mathrm{~cm}{ }^{-2}, V_{\mathrm{oc}}=0.78 \mathrm{~V}\right.$ and $\left.\mathrm{FF}=0.56\right)$ and $5.50\left(J_{\mathrm{sc}}=11.67 \mathrm{~mA}\right.$ $\mathrm{cm}^{-2}, V_{\text {oc }}=0.76 \mathrm{~V}$ and $\mathrm{FF}=0.62$ ), respectively. The improvement in the PCE is mainly due to the enhancement in both $J_{\mathrm{sc}}$ and FF. The improvement in the value of $J_{\mathrm{sc}}$ for device $\mathrm{B}$ and $\mathrm{C}$ is consistent with the IPCE spectra of the devices, i.e. the values of IPCE are higher for B and C as compared to device A throughout the whole wavelength range of measurements. The $J_{\mathrm{sc}}$ values estimated from the integration of IPCE spectra of the corresponding devices are $8.24 \mathrm{~mA} \mathrm{~cm}^{-2}, 10.13 \mathrm{~mA} \mathrm{~cm}^{-2}$ and $11.54 \mathrm{~mA} \mathrm{~cm}^{-2}$ for devices $\mathrm{A}, \mathrm{B}$ and $\mathrm{C}$, respectively. These values are consistent with the values estimated from $J-V$ characteristics of the corresponding devices. The improvement in the PCE after additional treatment i.e. solvent addition and subsequent thermal annealing has been mainly attributed to the significant enhancement in both $J_{\mathrm{sc}}$ and $\mathrm{FF}$ and may be originated from the enhanced absorption, better morphology of the active layer and higher and more balanced charge carrier mobilities.

To obtain information about the improved performance of the devices $\mathrm{B}$ and $\mathrm{C}$, we have measured the optical absorption spectra of the blends used for devices A, B and $\mathrm{C}$, i.e. active layer cast from THF, pyridine/THF and pyridine/THF (thermally annealed) and are shown in Fig. 5. As shown in Fig. 5, the absorption intensity of the pyridine/THF cast blend film is enhanced and ICT band corresponds to VC117 which is red shifted as compared to the THF cast blend film which is related to the enhanced $\pi-\pi$ stacking between the molecule backbones..$\stackrel{38}{\text { For }}$ the film with further thermal annealing, the absorption intensity was further improved. These results indicate that the solvent addition and subsequent thermal annealing improved the light harvesting ability of the active layer and is one of the reasons for the enhancement of $J_{\mathrm{sc}}$ of the devices B and C.

The difference in PCE of the solar cell, when the active layer was spin-cast from pyridine/THF solution, may be the difference in exciton dissociation efficiency, after the exciton generation. Photoluminescence (PL) quenching provides direct evidence for the exciton dissociation, which influences the $J_{\text {sc }}$ and is used as a measure of photoinduced charge transfer between the donor and acceptor interface present in the active layer. PL was measured to investigate the exciton dissociation efficiency. Fig. 7 shows the PL spectra of spin coated VC117(THF cast) and VC117:PC ${ }_{71} \mathrm{BM}(1: 1)$ 
(THF and pyridine/THF cast) blend films. As can be seen from this figure, the pristine VC117 exhibits PL emission with a peak around $716 \mathrm{~nm}$. Blending VC117 with $\mathrm{PC}_{71} \mathrm{BM}$, the PL peak is quenched. The degree of quenching increases with the addition of pyridine. This effective PL quenching suggest that the exciton separation was more efficient in the active layer cast from pyridine/THF as compared to that for the THF cast active layer. The more effective quenching in the pyridine/THF cast film than in the THF cast film implies two possibilities: (i) better exciton dissociation in the pyridine/THF cast film and (ii) a larger interfacial area between the VC117 and $\mathrm{PC}_{71} \mathrm{BM}$ through the optimal nanoscale phase separation. The former could be ruled out, because this is affected mainly by the energy difference between the HOMO of the donor and LUMO of the acceptor used in the blend. The second mechanism is mainly responsible for the effective PL quenching as confirmed by the active layer film morphology studies. Thus, the optimized phase separation and crystallinity of the active layer are important factors for efficient exciton dissociation. The morphology and quenching of PL intensity revealed that the active layer processed with pyridine/THF exhibits more favorable features for higher $J_{\text {sc }}$.

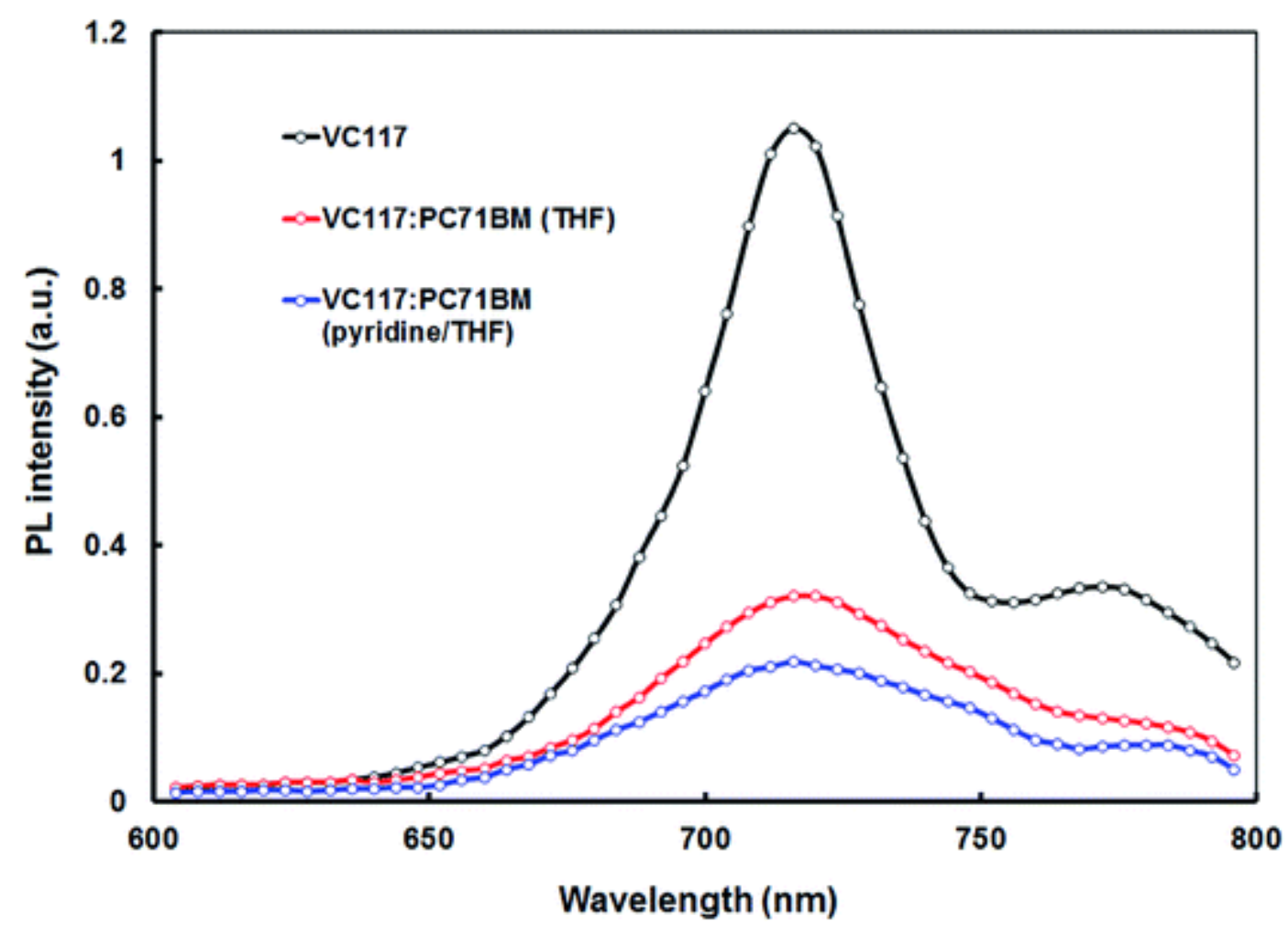

Fig. 7 PL spectra of VC117, VC117:PC ${ }_{71} B M(T H F)$ and VC117:PC $C_{71} B M$ (pyridine/THF) thin films. 
The morphology of the thin film was characterized by transmission electron microscopy (TEM) and Fig. 8 shows the active layers employed for devices A, B and C. The thin film processed with THF forms large phase separated domains of sizes $90-100 \mathrm{~nm}$ which are significantly larger than the exciton diffusion length. This large scale phase separation affects the exciton dissociation into free charge carrier and their transportation and leads to the reduction in $J_{\mathrm{sc}}$ and FF. The film cast from the pyridine/THF had smaller domain sizes and were further reduced up to $20-25 \mathrm{~nm}$ with additional thermal annealing. The better morphology and optimized interpenetrating networks of blend active layer films with TA and SATA treatment lead to increased donor-acceptor interfacial area and hole mobility, which may increase the exciton dissociation and charge transport efficiency and reduces the charge carrier recombination, thus resulting in higher $J_{s c}$ and $F F .{ }^{39}$

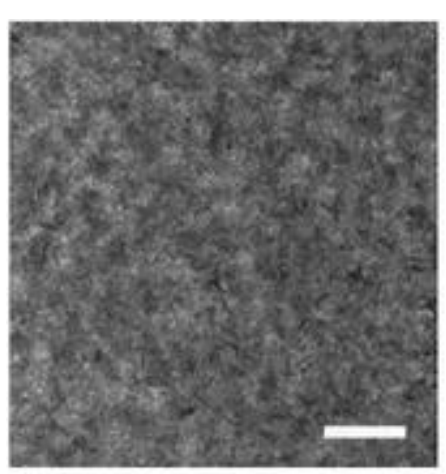

(a)

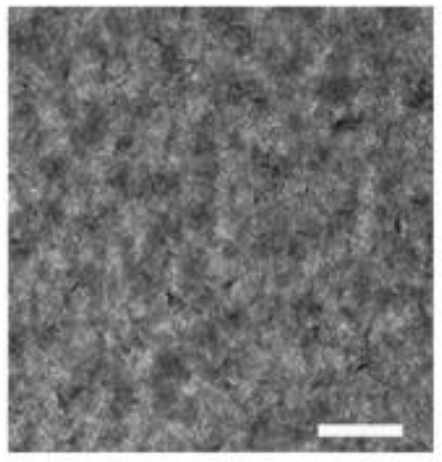

(b)

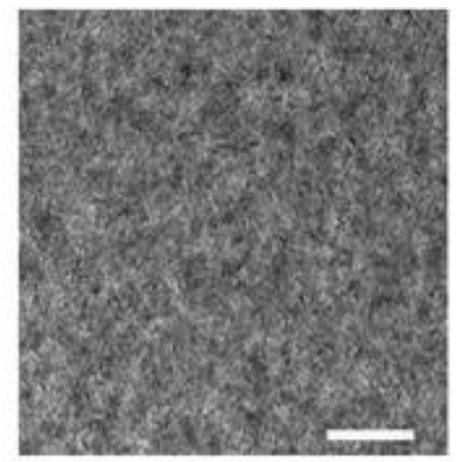

(c)

Fig. 8 TEM morphology of thin films prepared with (a) THF (b) pyridine/THF, and (c) pyridine/THF (thermal annealed). The scale bar is $300 \mathrm{~nm}$.

The crystallinity of the active layer also plays an important role in charge transport and collection, thereby increasing the overall PCE of the organic solar cell. To obtain information about the change in the crystallinity of the VC117: $\mathrm{PC}_{71} \mathrm{BM}$ film with the addition of pyridine in the host solvent, prior to spin casting, we have recorded the X-ray diffraction (XRD) pattern of the spin cast thin film processed with and without pyridine additive. In addition, we have also recorded the XRD patterns of the pristine VC117 thin film cast from THF and pyridine/THF solvents, for comparison (ESI figure ${ }^{\dagger}$ ). The pristine VC117 cast from THF as well as from pyridine/THF shows a strong diffraction peak at $2 \vartheta=7.22^{\circ}$, but the intensity of the latter is stronger than the one of the former, indicating that the crystallinity of the film increased with the addition of the pyridine additive. The blend VC117: $\mathrm{PC}_{71} \mathrm{BM}$ cast from THF (black color Fig. 9a) also shows a diffraction peak at around $2 \vartheta=7.22^{\circ}$, corresponding to the VC117 unit but its intensity becomes weak, suggesting an effective mixing of $\mathrm{PC}_{71} \mathrm{BM}$ and VC117. However, this diffraction peak becomes more intense in the corresponding blend cast from the pyridine/THF solvent, while its width at half maximum height is decreased. These results indicate that the blend film cast from the THF solvent has low crystallinity, while in the case of the blend film cast from the pyridine/THF solvent, the crystallinity and $\pi$ conjugation ofVC117 in the blend 
increases. The intensity further increased with additional thermal annealing. This is probably due to the difference in the boiling point of THF and pyridine that makes the spin coated film to dry slowly, assisting in the formation of a better self ordered structure of the blend. The increase in the crystallinity leads to an enhancement in the light absorption properties of the active layer and higher hole mobility in the blend film, leading to the increase in $J_{s c}, F F$ and PCE of the organic solar cell.

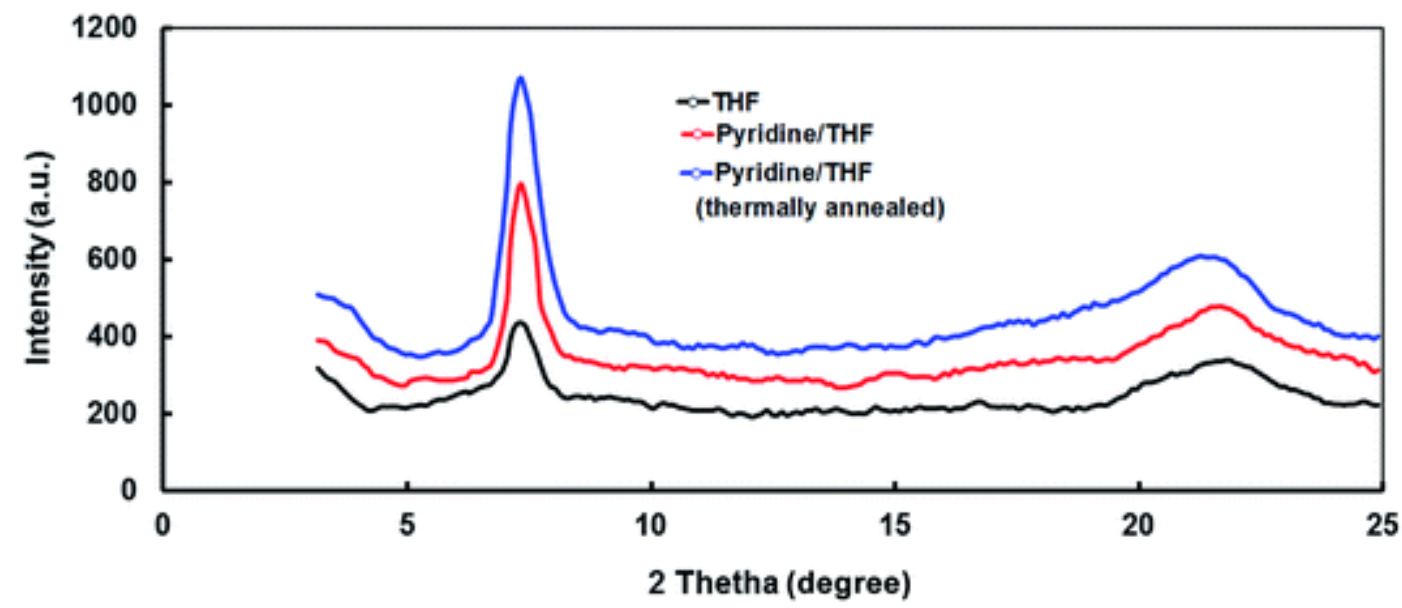

Fig. 9 XRD patterns of the VC117: $\mathrm{PC}_{71} \mathrm{BM}$ films processed with THF, pyridine/THF and pyridine/THF (thermal annealed) under different conditions.

he charge carrier mobility in the BHJ active layer is critical for the BHJ organic solar cell efficiency because the photogenerated charges extract at the electrode depends on the competition between carrier sweep out, which is limited by the carrier mobility, and the loss of photogenerated carriers by recombination. ${ }^{40}$ The hole and electron mobilities of the optimizedVC117: $\mathrm{PC}_{71} \mathrm{BM} \mathrm{BHJ}$ active layer processed with/without pyridine additive and subsequent thermal annealing were estimated by a space charge limited current (SCLC) method ( $J-V$ characteristics in the dark) using the hole only device (ITO/PEDOT:PSS/VC117:PC ${ }_{71} \mathrm{BM} / \mathrm{Au}$ ) and the electron only device (ITO/Al/VC117:PC ${ }_{71} \mathrm{BM} / \mathrm{Al}$ ), respectively. The results were analyzed using the SCLC model described by the Mott-Gurney law which includes a small field dependent term, as seen in following equation. ${ }^{41}$

$$
J=\frac{9}{8} \varepsilon_{\mathrm{r}} \varepsilon_{\mathrm{o}} \mu_{\mathrm{o}} \frac{\left(V_{\mathrm{app}}-V_{\mathrm{bi}}\right)^{2}}{L^{3}} \exp \left(\beta \sqrt{\frac{V_{\mathrm{app}}-V_{\mathrm{bi}}}{L}}\right)
$$

where $\varepsilon_{\mathrm{r}} \varepsilon_{\mathrm{o}}$ is the dielectric permittivity of the active layer, $L$ is the thickness of the active layer, $V_{\text {app }}$ is the applied voltage, $V_{\mathrm{bi}}$ is the built in voltage, $\mu_{\mathrm{o}}$ is the zero field mobility, and $\beta$ is the field activation factor. 
The $J-V$ characteristics of the hole only device in the dark are shown in Fig. 10. The fitting of the experimental results (solid lines) revealed that the hole mobilities are found to be $6.21 \times 10^{-6} \mathrm{~cm}^{2} \mathrm{~V}^{-1} \mathrm{~s}^{-1}, 5.05 \times 10^{-5} \mathrm{~cm}^{2} \mathrm{~V}^{-1} \mathrm{~s}^{-1}$ and $8.45 \times 10^{-5} \mathrm{~cm}^{2} \mathrm{~V}^{-1} \mathrm{~s}^{-1}$ for the device without and with pyridine additives and subsequent thermally annealed, respectively. Although the thickness of the active layer influences the charge carrier mobility, and we took much care to ensure alike film thickness of the active layer (90 $\mathrm{nm} \pm 5 \mathrm{~nm}$ ) and avoid substantial influence of this parameter on the devices' charge mobility. The increase in the pyridine additives and thermal annealing agrees well with the results revealed by the morphology analysis, in which the domain size and crystallinity decreases and increases, respectively, with the pyridine additives and subsequent thermal annealing. The electron mobility of the active layer processed without/with pyridine additive and thermal annealing is quite similar, i.e. $2.29 \times$ $10^{-4} \mathrm{~cm}^{2} \mathrm{~V}^{-1} \mathrm{~s}^{-1}, 2.34 \times 10^{-4} \mathrm{~cm}^{2} \mathrm{~V}^{-1} \mathrm{~s}^{-1}$, and $2.38 \times 10^{-4} \mathrm{~cm}^{2} \mathrm{~V}^{-1} \mathrm{~s}^{-1}$, respectively. The ratio of electron to hole mobilities in the active layer processed without/with additive and subsequent thermal annealing is found to be about 36, 4.63 and 2.81, respectively. Therefore, it seems that in the active layer processed with pyridine and subsequent thermal annealing, the charge carrier transports are more balanced, a feature that increases the short circuit current, $J_{\mathrm{sc}}$ and the fill factor, FF, of the device, leading to a higher overall PCE value (Table 3). 


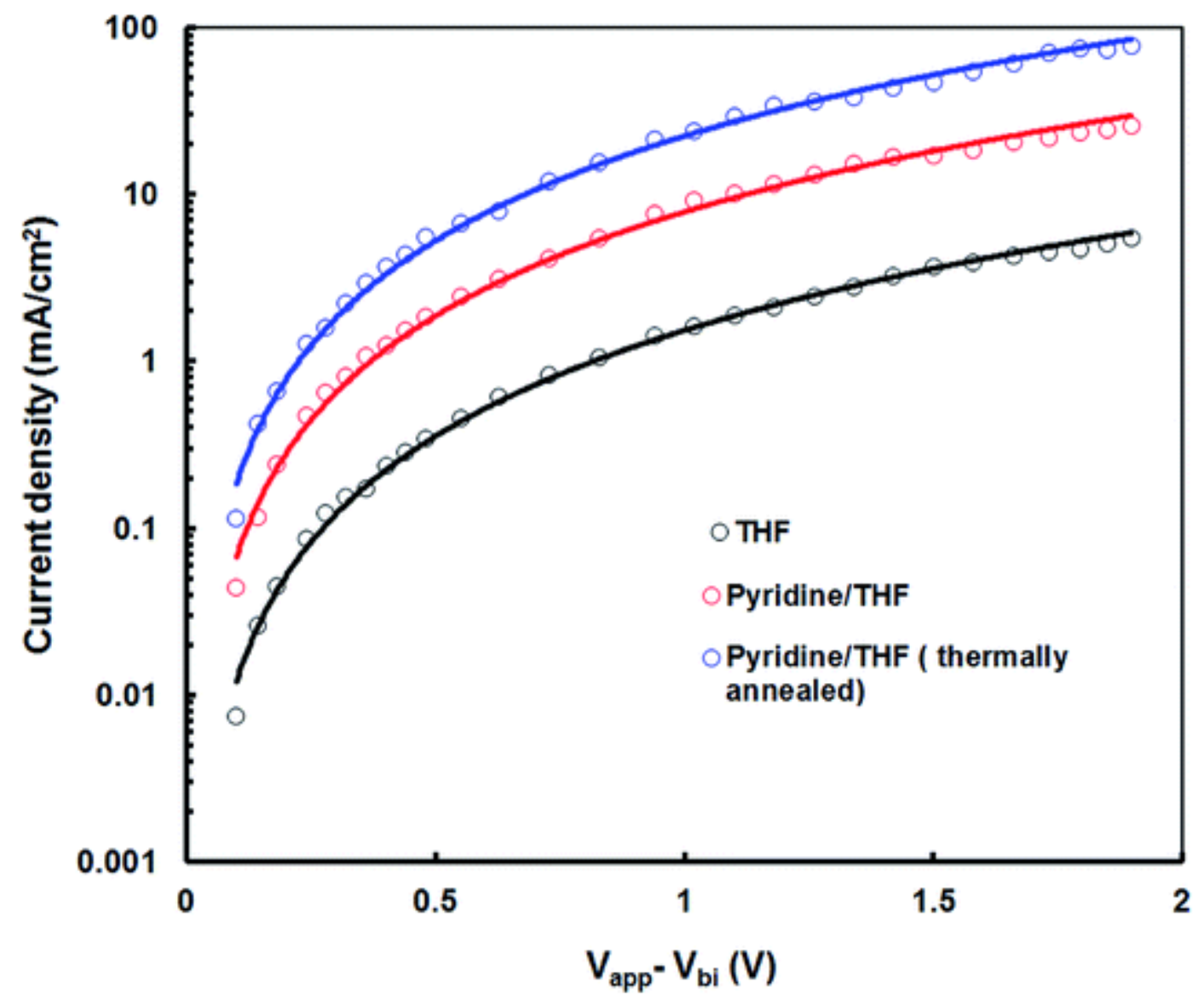

Fig. 10 Current-voltage characteristics of hole only devices in the dark based onVC117:PC ${ }_{71} B M$ blends processed under different conditions to measure the hole mobility.

We have estimated the series resistance $\left(R_{\mathrm{s}}\right)$ and shunt resistance $\left(R_{\mathrm{sh}}\right)$ from the slope of the $J-V$ characteristics of the devices, under illumination, around the $V_{\mathrm{oc}}$ and $J_{\mathrm{sc}}$, respectively, and compiled them in Table 3 . In general, the $R_{\mathrm{s}}$ of the organic solar cell is composed of the bulk resistance of the active layer and depends on the charge transport ability within the active layer and the morphology of the active layer. It can be seen from Table 1 that $R_{\mathrm{s}}$ of the device processed with the pyridine/THF solvent is significantly lower than that processed with THF and further decreased, which may be attributed to better morphology and balanced charge transport. Therefore, the higher boiling point of pyridine offers more time for the adjustment of molecular aggregation to improve the morphology and interpenetrating pathway network for charge transport, reducing the $R_{\mathrm{s}}$ and increasing the $J_{\mathrm{sc}}$ and FF. The increase in $R_{\mathrm{sh}}$ is related to the 
decrease in leakage current and depends upon the intermolecular interaction (or electronic) coupling between the donor and acceptor materials in the active layer. Therefore, the slight decrease in the $V_{\text {oc }}$ of the device processed with the additive could be due to the increasing intermolecular interaction between the donor and acceptor.

We further studied the effect on the charge generation in VC117: $\mathrm{PC}_{71} \mathrm{BM} \mathrm{BHJ}$ solar cells i.e. devices $\mathrm{A}, \mathrm{B}$ and $\mathrm{C}$ by investigating the saturation point where the internal field is large enough to sweep out all the carriers to the electrodes prior to recombination. Fig. 11 shows the variation of photocurrent density $\left(J_{\mathrm{ph}}\right)$ with the internal voltage $\left(V_{\text {int }}\right)$ of the device processed with THF and pyridine/THF and pyridine/THF (solvent additive), under illumination at $100 \mathrm{~mW} \mathrm{~cm}^{-2} . J_{\mathrm{ph}}$ is estimated as $J_{\mathrm{ph}}=J_{\mathrm{L}}-J_{\mathrm{d}}$, where $J_{\mathrm{L}}$ and $J_{\mathrm{d}}$ are the current density under illumination and in the dark, respectively. ${ }^{41 b} V_{\text {int }}$ is determined as $V_{\text {int }}=V_{\mathrm{o}}-V$, where $V_{\mathrm{o}}$ is the voltage at which $J_{\mathrm{ph}}$ is zero and $V$ is the applied voltage. Therefore, $V_{\text {int }}$ corresponds to the strength of the electric field within the device that is needed to extract the charge carriers. As it can be seen from Fig. $11, J_{\mathrm{ph}}$ increases linearly with voltage at low $V_{\text {int }}$, but saturates at $\operatorname{high} V_{\text {int }}(1.8 \mathrm{~V}$ or higher). Therefore, we assume that almost all the photogenerated charge carriers within the device are collected at high $V_{\mathrm{int}}$ and $J_{\mathrm{ph}}$ saturated and independent of $V_{\text {int }}$. The $J_{\mathrm{ph}}$ at $V_{\mathrm{int}}=2.9 \mathrm{~V}$ is found to be at about $15.03 \mathrm{~mA} \mathrm{~cm}{ }^{-2}, 16.07$ $\mathrm{mA} \mathrm{cm}{ }^{-2}$ and $16.29 \mathrm{~mA} \mathrm{~cm}^{-2}$ for the device A, B and C, respectively, suggesting that the charge generation in the devices is influenced by the solvent additives. The charge collection probability $\left(P_{c}\right)$ of the solar cells based on the active layers processed with THF, pyridine/THF and pyridine/THF (thermally annealed) was estimated as $P_{\mathrm{c}}=J_{\mathrm{sc}} / J_{\mathrm{ph}, \text { sat }}$, and was found to be about $0.56,0.64$ and 0.72 , respectively. The low charge generation could be explained in terms of inefficient photon absorption and/or charge separation. Concerning the former parameter, the UV-visible absorption bands of the $\mathrm{VC117}: \mathrm{PC}_{71} \mathrm{BM} \mathrm{BHJ}$ active layer processed with pyridine additive are stronger than those of the corresponding one processed without additive (see Fig. 5), proving that there is indeed a difference in photon absorption. Nevertheless, the charge separation is another significant parameter that cannot be neglected, as there is a difference between the two devices in terms of domain size of phase separation, as confirmed by TEM images, which is critical to charge recombination. So as the excitons are generated away from the D/A interfaces, they are not able to reach the interfaces in the large domain size of phase separation in the device processed in THF and the chances of recombination before the excitons are dissociated into free charge carriers are increased. However, the solvent addition reduces this domain size and increases the D/A interfacial area so that more excitons are dissociated into free charge carriers. 


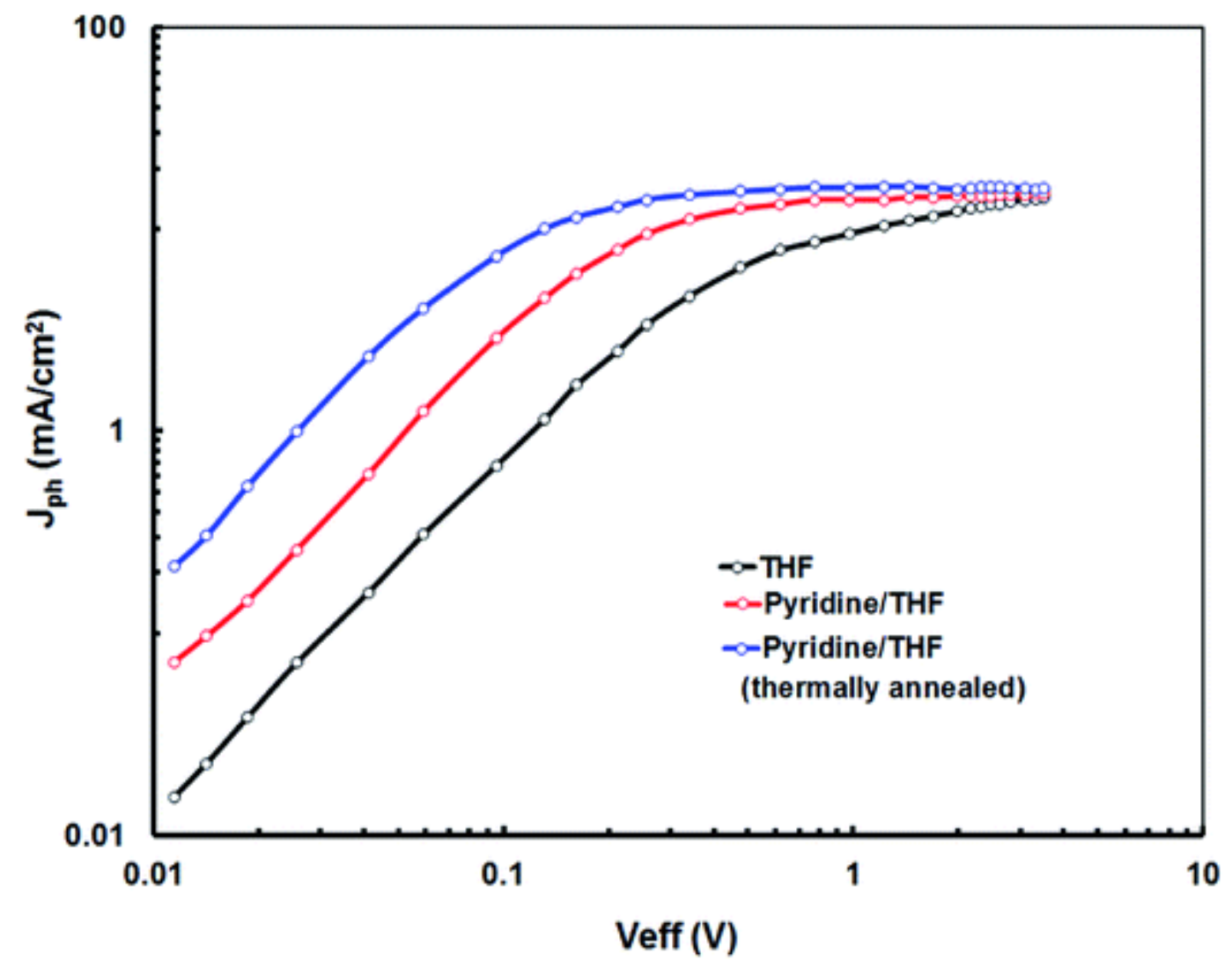

Fig. 11 Photocurrent density $\left(J_{\text {ph }}\right)$ variation with internal voltages $\left(V_{\text {in }}\right)$ for VC117:PC $\mathrm{C}_{71} \mathrm{BM}$ devices processed under different conditions.

\section{Conclusions}

In this report we presented the synthesis, optical and electrochemical properties of an A $-\pi-D-\pi-A$ porphyrin small molecule in which ethyl rhodanine end capping groups were linked to the core porphyrin donor via an octyl thiophene-ethynylene $\pi$ bridge i.e.VC117, was used as the electron donor for the fabrication of solution processed $\mathrm{BHJ}$ solar cells along with $\mathrm{PC}_{71} \mathrm{BM}$ as the electron acceptor. The optical and electrochemical properties of VC117 suggest that the VC117: $\mathrm{PC}_{71} \mathrm{BM}$ blend can effectively harvest photons and transfer electrons from $\mathrm{VC117}$ to $\mathrm{PC}_{71} \mathrm{BM}$, resulting in a photovoltaic effect. The solar cell based on a VC117:PC ${ }_{71} \mathrm{BM}$ BHJ active layer with an optimized $1: 1$ weight ratio, processed from THF, displayed a PCE value of $2.95 \%$. In order to improve the efficiency of this organic solar cell, the VC117: $\mathrm{PC}_{71} \mathrm{BM} \mathrm{BHJ}$ active layer was processed from a solvent mixture of $4 \% \mathrm{v} / \mathrm{v}$ of pyridine in THF and subsequent thermal annealing. The PCE value of the resulting devices $\mathrm{B}$ and $\mathrm{C}$ was improved up to $4.46 \%$ and $5.50 \%$, respectively, as a result of the enhancement of their $J_{\mathrm{sc}}$ and FF values, parameters that are related to the charge generation/separation/mobility/transport that are found to be significantly improved by 
the morphology and crystallinity change of the active layer upon addition of pyridine and further improved with thermal annealing.

\section{Acknowledgements}

We would like to thank MINECO for the project CTQ2013-47183 R and the support through Severo Ochoa Excellence Accreditation 2014-2018 (SEV-2013-0319). We are also thankful to the Material Science laboratory, MNIT, Jaipur for the availability characterization.

References

1 (a) F. C. Krebs, N. Espinosa, M. H“osel, R. R. Søndergaard and

M. Jørgensen, Adv. Mater., 2014, 26, 29; (b) W. Li,

W. S. C. Roelofs, M. Turbiez, M. M. Wienk and

R. A. J. Janssen, Adv. Mater., 2014, 26, 3304; (c) L. Bian,

E. Zhu, J. Tang, W. Tang and F. Zhang, Prog. Polym. Sci.,

2012, 37, 1292; (d) S. H. Liao, H. J. Jhuo, P. N. Yeh,

Y. S. Cheng, Y. L. Li, Y. H. Lee, S. Sharma and S. A. Chen,

Sci. Rep., 2014, 4, 6813; (e) A. J. Heeger, Adv. Mater., 2014,

26, 10; (f) X. Guo, M. Baumgarten and K. M“ullen, Prog.

Polym. Sci., 2013, 38, 1832.

2 (a) Y. Liu, J. Zhao, Z. Li, C. Mu, W. Ma, H. Hu, K. Jiang, H. Lin,

H. Ade and H. Yan, Nat. Commun., 2014, 5, 5293; (b)

C. C. Chen, W. H. Chang, K. Yoshimura, K. Ohya, J. You,

J. Gao, Z. Hong and Y. Yang, Adv. Mater., 2014, 26, 5670; (c)

C. Z. Li, C. Y. Chang, Y. Zang, H. X. Ju, C. C. Chueh,

P. W. Liang, N. Cho, D. S. Ginger and A. K.-Y. Jen, Adv.

Mater., 2014, 26, 6262; (d) H. Kang, S. Kee, K. Yu, J. Lee,

G. Kim, J. Kim, J. R. Kim, J. Kong and K. Lee, Adv. Mater., 
$2015,27,1408$.

3 J. You, L. Dou, K. Yoshimura, T. Kato, K. Ohya, T. Moriarty, K. Emery, C.-C. Chen, J. Gao, G. Li and Y. Yang, Nat. Commun., 2013, 4, 1446.

4 (a) P. M. Beaujuge and J. M. J. Fr'echet, J. Am. Chem. Soc., 2011, 133, 20009; (b) Y. Li, Acc. Chem. Res., 2012, 45, 723;

(c) H. Zhou, L. Yang and W. You, Macromolecules, 2012, 45, 607; (d) C. Z. Li, C. Y. Chang, Y. Zang, H. X. Ju, C. C. Chueh, P. W. Liang, N. Cho, D. S. Ginger and A. K. Jen, Adv. Mater., 2014, 26, 6262; (e) L. Lu and L. Yu, Adv. Mater., 2014, 26, 4413.

5 (a) Y. J. He, H. Y. Chen, J. H. Hou and Y. F. Li, J. Am. Chem. Soc., 2010, 132, 1377; (b) A. E $\square$ aiha, J. Sun, I. Hill and G. Welch, J. Mater. Chem. A, 2014, 2, 1201. 6 (a) C. He, S. Su, M. Xu, H. Wu and Y. Cao, Nat. Photonics, 2012, 6, 591; (b) L. Dou, J. You, Z. Hong, Z. Xu, G. Li, R. A. Street and Y. Yang, Adv. Mater., 2013, 25, 6642; (c) C. Duan, K. Zhang, C. Zhong, F. Huang and Y. Cao, Chem. Soc. Rev., 2013, 42, 9071; (d) J. Kong, I. W. Hwang and K. Lee, Adv. Mater., 2014, 26, 6275; (e) M. T. Dang and J. D. Wuest, Chem. Soc. Rev., 2013, 42, 9105; (f) T. Ameri, N. Li and C. J. Brabec, Energy Environ. Sci., 2013, 6, 2390; (g) J. Mei and Z. Bao, Chem. Mater., 2014, 26, 604; (h) L. Ye, S. Zhang, L. Huo, M. Zhang and J. Hou, Acc. Chem. Res., $2014,47,1595$.

7 H. J. Song, D. H. Kim, E. J. Lee and D. K. Moon, J. Mater. Chem. A, 2013, 1, 6010-6020. 
8 (a) B. Walker, C. Kim and T. Q. Nguyen, Chem. Mater., 2011, 23, 470; (b) J. Roncali, P. Leriche and P. Blanchard, Adv. Mater., 2014, 26, 3821; (c) A. Mishra and P. B“auerle, Angew. Chem., Int. Ed., 2012, 51, 2020; (d) Y. Lin, Y. Li and X. Zhan, Chem. Soc. Rev., 2012, 41, 4245; (e) Y. Sun, G. Welch, W. Leong, C. Takacs, G. C. Bazan and A. J. Heeger, Nat. Mater., 2012, 11, 44; (f) J. E. Coughlin, Z. B. Henson, G. C. Welch and G. C. Bazan, Acc. Chem. Res., 2014, 47, 257.

9 (a) A. K. K. Kyaw, D. H. Wang, D. Wynands, J. Zhang, T. Q. Nguyen, G. C. Bazan and A. J. Heeger, Nano Lett., 2013, 13, 3796; (b) J. Zhou, Y. Zuo, X. Wan, G. Long, Q. Zhang, W. Ni, Y. Liu, Z. Li, G. He, C. Li, B. Kan, M. Li and Y. Chen, J. Am. Chem. Soc., 2013, 135, 8484; (c) Q. Zhang, B. Kan, F. Liu, G. Long, X. Wan, X. Chen, Y. Zuo, W. Ni, H. Zhang, M. Li, Z. Hu, F. Huang, Y. Cao, Z. Liang, M. Zhang, T. P. Russell and Y. Chen, Nat. Photonics, 2014, 9, 35-41; (d) V. Gupta, A. K. K. Kyaw, D. H. Wang, S. Chand, G. C. Bazan and A. J. Heeger, Sci. Rep., 2013, 3, 1965; (e) Y. Liu, C. C. Chen, Z. Hong, J. Gao, Y. Michael Yang, H. Zhou, L. Dou, G. Li and Y. Yang, Sci. Rep., 2013, 3, 3356; (f) B. Kan, Q. Zhang, M. Li, X. Wan, W. Ni, G. Long, Y. Wang, X. Yang, H. Feng and Y. Chen, J. Am. Chem. Soc., 2014, 136, 15525-15532; (g) B. Kan, M. Li, Q. Zhang, F. Liu, X. Wan, Y. Wang, W. Ni, G. Long, X. Yang, H. Feng, Y. Zuo, M. Zhang, F. Huang, Y. Cao, T. P. Russell and Y. Chen, J. Am. Chem. Soc., 2015, 137, 3886. 
10 (a) C. W. Tang and A. C. Albrecht, Nature, 1975, 254, 507; (b)

A. Goetzberger, C. Hebling and H. W. Schock, Mater. Sci.

Eng., R, 2003, 40, 1; (c) L. L. Li and E. W.-G. Diau, Chem.

Soc. Rev., 2013, 42, 291.

11 (a) T. Umeyama, T. Takamatsu, N. Tezuka, Y. Matano, Y. Araki, T. Wada, O. Yoshikawa, T. Sagawa, S. Yoshikawa and H. Imahori, J. Phys. Chem. C, 2009, 113, 10798; (b)

S. J. Lee, K. L. Mulfort, X. Zuo, A. J. Goshe, P. J. Wesson,

S. T. Nguyen, J. T. Hupp and D. M. Tiede, J. Am. Chem. Soc., 2008, 130, 836-838; (c) M. S. Kang, J. B. Oh, K. D. Seo, H. K. Kim, J. Park, K. Kim and N. G. Park, J. Porphyrins Phthalocyanines, 2009, 13, 798; (d) H. Imahori, T. Umeyama and S. Ito, Acc. Chem. Res., 2009, 42, 1809; (e) R. B. Ambre, G.-F. Chang, M. R. Zanwar, C.-F. Yao, E. W.-G. Diau and C.-H. Hung, Chem.-Asian J., 2013, 8, 2144-2153.

12 (a) M. Urbani, M. Gr“atzel, M. K. Nazeeruddin and T. Torres, Chem. Rev., 2014, 114, 12330; (b) T. Higashino and H. Imahori, Dalton Trans., 2015, 44, 448-463; (c) M. K. Panda, K. Ladomenou and A. G. Coutsolelos, Coord. Chem. Rev., 2012, 256, 2601-2627; (d) K. Ladomenou, T. N. Kitsopoulos, G. D. Sharma and A. G. Coutsolelos, RSC Adv., 2014, 4, 21379.

13 (a) S. Mathew, A. Yella, P. Gao, R. Humphry-Baker, B. F. E. Curchod, N. Ashari-Astani, I. Tavernelli, U. Rothlisberger, M. K. Nazeeruddin and M. Gr“atzel, Nat. Chem., 2014, 6, 242-247; (b) A. Yella, H.-W. Lee, H. N. Tsao, C. Yi, A. K. Chiran, M. K. Nazeeruddin, 
E. W.-G. Diau, C.-Y. Yeh, S. M. Zakeeruddin and

M. Gratzel, Science, 2011, 334, 629.

14 (a) J. Hatano, N. Obata, S. Yamaguchi, T. Yasuda and

Y. Matsuo, J. Mater. Chem., 2012, 22, 19258; (b)

T. Yamamoto, J. Hatano, T. Nakagawa, S. Yamaguchi and

Y. Matsuo, Appl. Phys. Lett., 2013, 102, 013305; (c)

T. Nakagawa, J. Hatano and Y. Matsuo, J. Porphyrins

Phthalocyanines, 2014, 18, 735-740; (d) Y. Matsuo,

J. Hatano and T. Nakagawa, J. Phys. Org. Chem., 2014, 27,

87-93; (e) T. Sato, T. Nakagawa, H. Okada and Y. Matsuo, J. Porphyrins Phthalocyanines, 2015, 19, 451-458.

15 (a) Y. Huang, L. Li, X. Peng, J. Peng and Y. Cao, J. Mater. Chem., 2012, 22, 21841; (b) L. Li, Y. Huang, J. Peng, Y. Cao and X. Peng, J. Mater. Chem. A, 2013, 1, 2144; (c)

G. D. Sharma, D. Daphnomili, S. Biswas and

A. G. Coutsolelos, Org. Electron., 2013, 14, 1811; (d)

G. D. Sharma, G. E. Zervaki, P. A. Angaridis,

T. N. Kitsopoulos and A. G. Coutsolelos, J. Phys. Chem. C, 2014, 118, 5968; (e) J. Kesters, P. Verstappen,

M. Kelchtermans, L. Lutsen, D. Vanderzande and W. Maes, Adv. Energy Mater., DOI: 10.1002/aenm.201500218.

16 (a) H. Qin, L. Li, F. Guo, S. Su, J. Peng, Y. Cao and X. Peng, Energy Environ. Sci., 2014, 7, 1397; (b) K. Gao, L. Li, T. Lai,

L. Xiao, Y. Huang, F. Huang, J. Peng, Y. Cao, F. Liu,

T. P. Russell, R. A. J. Janssen and X. Peng, J. Am. Chem.

Soc., 2015, 137, 7282-7285.

17 (a) Y. Liu, X. Wan, B. Yin, J. Zhou, G. Long, S. Yin and

Y. Chen, J. Mater. Chem., 2010, 20, 2464; (b) K. Schulze,

C. Uhrich, R. Schuppel, K. Leo, M. Pfeiffer, E. Brier,

E. Reinold and P. Bauerle, Adv. Mater., 2006, 18, 2872.

18 (a) Y. S. Liu, X. Wan, F. Wang, J. Zhou, G. Long, J. Tian and

Y. Chen, Adv. Mater., 2011, 23, 5387; (b) Y. S. Liu, X. Wan,

F. Wang, J. Zhou, G. Long, J. Tian, J. You, Y. Yang and

Y. Chen, Adv. Energy Mater., 2011, 1, 771; (c) J. Y. Zhou,

X. Wan, Y. Liu, G. Long, F. Wang, Z. Li, Y. Zuo, C. Li and

Y. Chen, Chem. Mater., 2011, 23, 4666; (d) Y. S. Liu,

Y. Yang, C. C. Chen, Q. Chen, L. Dou, Z. Hong, G. Li and Y. Yang, Adv. Mater., 2013, 25, 4657.

19 (a) Z. Li, G. He, X. Wan, Y. Liu, J. Zhou, G. Long, Y. Zuo, M. Zhang and Y. Chen, Adv. Energy Mater., 2012, 2, 74; (b)

J. Y. Zhou, X. Wan, Y. Liu, Y. Zuo, Z. Li, G. He, G. Long, W. Ni, C. Li, X. Su and Y. Chen, J. Am. Chem. Soc., 2012, 134, 16345; (c) J. Y. Zhou, Y. Zuo, X. Wan, G. Long,

Q. Zhang, W. Ni, Y. Liu, Z. Li, G. He, C. Li, B. Kan, M. Li

and Y. Chen, J. Am. Chem. Soc., 2013, 135, 8484.

20 C. Vijay Kumar, L. Cabau, E. N. Koukaras, G. D. Sharma and 
E. Palomares, Nanoscale, 2015, 7, 179.

21 J. Zhou, X. Wan, Y. Liu, G. Long, F. Wang, Z. Li, Y. Zuo, C. Li and Y. Chen, Chem. Mater., 2011, 23, 4666-4668.

22 T. R. Sanchis, B. C. Guo, H. P. Wu, T. Y. Pan, H. W. Lee, S. R. Raga, F. Fabreqat-Santiago, J. Bisquert, C. Y. Yeh and E. W. G. Diau, Chem. Commun., 2012, 48, 4368.

23 T. E. O. Screen, K. B. Lawton, G. S. Wilson, N. Dolney, R. Ispasoiu, T. Goodson III, S. J. Martin, D. D. C. Bradley and H. L. Anderson, J. Mater. Chem., 2001, 11, 312.

24 (a) V. S.-Y. Lin, S. G. DiMagno and M. J. Therien, Science, 1994, 264, 1105; (b) C. Y. Lee, C. She, N. C. Jeong and J. T. Hupp, Chem. Commun., 2010, 46, 6090.

25 J. P. Perdew, K. Burke and M. Ernzerhof, Phys. Rev. Lett., 1996, 77, 3865.

26 A. Schafer, H. Horn and R. Ahlrichs, J. Chem. Phys., 1992, 97, 2571.

27 K. Eichkorn, O. Treutler, H. “Ohm, M. H“aser and R. Ahlrichs,

Chem. Phys. Lett., 1995, 240, 283.

28 (a) A. D. Becke, J. Chem. Phys., 1993, 98, 5648; (b) C. Lee,

W. Yang and R. G. Parr, Phys. Rev. B: Condens. Matter

Mater. Phys., 1988, 37, 785.

29 Y. Zhao and D. G. Truhlar, Theor. Chem. Acc., 2008, 120, 215.

30 M. J. Frisch, G. W. Trucks, H. B. Schlegel, G. E. Scuseria,

M. A. Robb, J. R. Cheeseman, G. Scalmani, V. Barone,

B. Mennucci, G. A. Petersson, H. Nakatsuji, M. Caricato,

X. Li, H. P. Hratchian, A. F. Izmaylov, J. Bloino, G. Zheng,

J. L. Sonnenberg, M. Hada, M. Ehara, K. Toyota,

R. Fukuda, J. Hasegawa, M. Ishida, T. Nakajima, Y. Honda,

O. Kitao, H. Nakai, T. Vreven, J. A. Montgomery Jr,

J. E. Peralta, F. Ogliaro, M. Bearpark, J. J. Heyd,

E. Brothers, K. N. Kudin, V. N. Staroverov, R. Kobayashi,

J. Normand, K. Raghavachari, A. Rendell, J. C. Burant,

S. S. Iyengar, J. Tomasi, M. Cossi, N. Rega, J. M. Millam, 
M. Klene, J. E. Knox, J. B. Cross, V. Bakken, C. Adamo,

J. Jaramillo, R. Gomperts, R. E. Stratmann, O. Yazyev,

A. J. Austin, R. Cammi, C. Pomelli, J. W. Ochterski,

R. L. Martin, K. Morokuma, V. G. Zakrzewski, G. A. Voth,

P. Salvador, J. J. Dannenberg, S. Dapprich, A. D. Daniels,

“O. Farkas, J. B. Foresman, J. V. Ortiz, J. Cioslowski and

D. J. Fox, Gaussian 03, Revision C.01, Gaussian, Inc.,

Wallingford, CT, 2004.

31 TURBOMOLE (version 5.6), Universitat Karlsruhe, 2000.

32 D. Jacquemin, E. A. Perp`ete, I. Cio $\square$ ni, C. Adamo, R. Valero,

Y. Zhao and D. G. Truhlar, J. Chem. Theory Comput., 2010, 6,

2071-2085.

33. R. Cowan, W. L. Leong, N. Banerji, G. Dennler and

A.J. Hegger, Adv. Funct. Mater., 2011, 21, 3083-3092.

34 Y. Li, Acc. Chem. Res., 2012, 45, 723.

35 (a) W. Ma, C. Yang, X. Gong, K. Lee and A. J. Heeger, Adv.

Funct. Mater., 2005, 15, 1617; (b) J. A. Mikroyannidis, A. N. Kabanakis, S. S. Sharma and G. D. Sharma, Adv. Funct. Mater., 2011, 21, 746.

36 (a) J. E. Coughlin, Z. B. Henson, G. C. Welch and G. C. Bazan, Acc. Chem. Res., 2013, 47, 257; (b) Y. Chen, X. Wan and G. Long, Acc. Chem. Res., 2013, 46, 2645.

37 (a) J. Peet, J. Y. Kim, N. E. Coates, W. L. Ma, D. Moses, A. J. Heeger and G. C. Bazan, Nat. Mater., 2007, 6, 497; (b) M. S. Su, C. Y. Kuo, M. C. Yuan, U. S. Jeng, C. J. Su and K. H. Wei, Adv. Mater., 2011, 23, 3315; (c) A. Tamayo,

T. Kent, M. Tantitiwat, M. A. Dante, J. Rogers and

T. Q. Nguyen, Energy Environ. Sci., 2009, 2, 1180; (d)

H. Fan, H. Shang, Y. Li and X. Zhan, Appl. Phys. Lett., 2010, 97, 133302; (e) B. Walker, C. Kim and T. Q. Nguyen, Chem. Mater., 2011, 23, 470.

38 M. C. Yuan, M. Y. Chiu, S. P. Liu, C. M. Chen and K. H. Wei, Macromolecules, 2010, 43, 6936.

39 B. Qi and J. Wang, Phys. Chem. Chem. Phys., 2013, 15, 8972.

40 (a) S. R. Cowan, A. Roy and A. J. Heeger, Phys. Rev. B:

Condens. Matter Mater. Phys., 2010, 82, 245207; (b)

a. K. K. Kyaw, D. H. Wang, C. Luo, Y. Cao, T. Q. Nguyen,

G. C. Bazan and A. J. Heeger, Adv. Energy Mater., 2014, 4, 
1301469.

41 (a) P. N. Murgatroyd, J. Phys. D: Appl. Phys., 1970, 3, 151; (b)

V. D. Mihailetchi, H. X. Xie, B. de Boer, L. J. A. Koster and

P. W. M. Blom, Adv. Funct. Mater., 2006, 16, 699.

42 J. Huang, C. Zhan, X. Zhang, Y. Zhao, Z. Lu, H. Jai, B. Jiang, J. Ye, S. Zhang, A. Tang, Y. Liu, Q. Pei and J. Jao, ACS Appl.

Mater. Interfaces, 2013, 5, 2030.

This 